\title{
Enantiospecific Response in Cross-Polarization Solid-State Nuclear-Magnetic-Resonance of Optically Active Metal Organic Frameworks
}

Eider San Sebastian ${ }_{\ddagger}^{\ddagger}$, Javier Cepeda ${ }^{a} \ddagger$, Uxua Huizi-Rayo ${ }^{\mathrm{a}}$, Alessio Terenzi ${ }^{\mathrm{b}_{\dagger}}$, Daniel FinkelsteinShapiro $^{c}$, Daniel Padro ${ }^{\mathrm{d}}$, Jose Ignacio Santose, Jon M. Matxain ${ }^{\mathrm{b}, \mathrm{f}}$, Jesus M. Ugalde, ${ }^{\mathrm{b}, *}$, V. Mujica ${ }^{\text {b,g,h, }, *}$

${ }^{a}$ Kimika Fakultatea, Kimika Aplikatua Saila, Euskal Herriko Unibertsitatea UPV/EHU, Manuel de Lardizabal Pasealekua 3, 20018 Donostia, Euskadi, Spain.

${ }^{\mathrm{b}}$ Donostia International Physics Center (DIPC), Manuel de Lardizabal Pasealekua 4, 20018 Donostia, Euskadi, Spain.

${ }^{\mathrm{c}}$ Division of Chemical Physics and Nanolund, Lund University, Box 124, 22100 Lund, Sweden

${ }^{\mathrm{d}}$ Center for Cooperative Research in Biomaterials (CIC biomaGUNE), Basque Research and Technology Alliance (BRTA), Paseo de Miramon 182, 20014, Donostia San Sebastián, Spain

e SGIker-UPV/EHU, "Joxe Mari Korta" Zentroa; Tolosa Hiribidea 72, 20018 Donostia, Spain.

${ }^{\mathrm{f}}$ Polimero eta Material Aurreratuak: Fisika, Kimika eta Teknologia Saila, Kimika Fakultatea, Euskal Herriko

Unibertsitatea UPV/EHU, Manuel de Lardizabal Pasealekua 3, 20018 Donostia, Euskadi, Spain

g Arizona State University, School of Molecular Sciences, Tempe, AZ 85287, U.S.A.

${ }^{\mathrm{h}}$ Ikerbasque Foundation and Donostia International Physics Center (DIPC), Manuel de Lardizabal Pasealekua 4, 20018 Donostia, Euskadi, Spain

$\dagger$ Current address: Department of Biological, Chemical and Pharmaceutical Sciences and Technologies, University of Palermo, Viale delle Scienze, Ed. 17, 90128 Palermo, Italy.

†These two authors contributed equally

\section{TABLE OF CONTENTS.}

S1. Materials and measurements.

S2. X-ray Data Collection and Structure Determination.

S3. Synthesis of compounds 1-L and 1-D.

S4. Thermogravimetric analysis.

S5. Powder X-ray Diffraction Analysis.

S6. $\quad$ FT-IR spectroscopy.

S7. Topological analysis.

S8. CD and UVA-Vis spectrometry of 1-L and 1-D.

S9. Experimental NMR part and statistical analysis

S10 Scanning Electron Microscope Imaging. 


\section{S1. Materials and Measurements.}

All chemicals were of the highest purity grade (99\% or more) and were used as commercially obtained. The use of ultrapure reagents in the synthesis of the MOFs rules out the necessity of recrystallization and purity tests. Still, thermal analysis and elemental analysis confirmed the integrity of the samples tested. Thermal analysis (TG/DTA) was performed on a TA Instruments SDT 2960 thermal analyser from room temperature up to $800{ }^{\circ} \mathrm{C}$ in a synthetic air atmosphere $\left(79 \% \mathrm{~N}_{2} / 21 \% \mathrm{O}_{2}\right)$ with a heating rate of $5{ }^{\circ} \mathrm{C} / \mathrm{min}$. Elemental analyses $(\mathrm{C}, \mathrm{H}$, and $\mathrm{N})$ were performed on a Fisons Instruments EA-1008 analyser. Metal content was determined by inductively coupled plasma (ICP-AES) analysis with a Horiba Yobin Yvon Activa spectrometer. The IR spectrum (KBr pellets) was recorded on a ThermoNicolet IR 200 spectrometer in the $4000-400 \mathrm{~cm}^{-1}$ spectral region.

\section{S2. X-ray Data Collection and Structure Determination.}

X-ray data collection of suitable single crystals of 1-L and 1-D was done at 100(2) K on an Agilent Technologies Super Nova diffractometer with monochromatic $\mathrm{Cu}-\mathrm{K} \alpha$ radiation $(\lambda=1.54184 \AA)$ and an Atlas CCD detector. The data reduction (including unit cell determinations, intensity data integrations, routine corrections for Lorentz and polarization effects and analytical absorption corrections) were performed using the CrysAlis Pro software package. ${ }^{1}$ Crystal structure was solved by direct methods using the SHELXT program ${ }^{2}$ and refined by full-matrix least-squares on $\mathrm{F}^{2}$ including all reflections and using anisotropic displacement parameters by means of the WINGX crystallographic package. ${ }^{3}$ During the data integration, it was observed that unit cell only indexed about half of the reflections, suggesting the occurrence of twinned specimens in both cases. Unusually large ADPs observed for many atoms as well as large $\mathrm{R}_{1}$ and $w \mathrm{R}^{2}$ agreement factors during the refinement stage further confirmed the latter. Accordingly, both structures were refined with the corresponding twin laws [(-1 00 / - $0.02150 .9633-0.0735$ / 0.0108 0.9812 -0.9632) and (-1 00 / $0.00950 .9616-0.0755$ / $0.0014-0.9837-0.9619)$ for 1-L and 1-D] including the two crystallographic domains (all reflections) in such a way that final percentages for the minor domain were estimated to be of $49 \%$ for 1-L but only of $0.04 \%$ for 1-D. Hydrogen atoms belonging to the tartrate ligands were located in the difference Fourier map and included with riding models as fixed contributions with isotropic thermal displacement parameters 1.2 and 1.5 times those of their parent carbon $(\mathrm{C}-\mathrm{H})$ and oxygen $(\mathrm{O}-\mathrm{H})$ atoms, respectively. The structure refinement converges with Flack parameters equal to $0.03(1)$ and 0.01(1), respectively for 1-L and 1-D, which confirms the chiral purity of both specimens. It is 
worth noticing that, given the microporous nature of the MOFs, their crystal structure contains channels filled with a variable number of lattice water molecules in within, which may slightly oscillate depending on the atmospheric conditions. As a consequence, despite the fact that both compounds are enantiomeric pairs, they do not possess the exact crystallographic formula but they differ in the content of one lattice water molecule, showing $\left\{\left[\mathrm{Y}_{2}\left(\mu_{4}-\mathrm{TAR}-\mathrm{L}\right)_{2}(\mu-\mathrm{TAR}-\mathrm{L})\left(\mathrm{H}_{2} \mathrm{O}\right)_{2}\right] \cdot 4 \mathrm{H}_{2} \mathrm{O}\right\}_{\mathrm{n}}(\mathbf{1 - L})$ and $\left\{\left[\mathrm{Y}_{2}\left(\mu_{4}-\mathrm{TAR}-\mathrm{D}\right)_{2}(\mu-\right.\right.$ TAR-D) $\left.\left.\left(\mathrm{H}_{2} \mathrm{O}\right)_{2}\right] \cdot 3 \mathrm{H}_{2} \mathrm{O}\right\}_{\mathrm{n}}(\mathbf{1 - D})$ formulae. The variation in the number of adsorbed waters is a common occurrence in MOFs. Given the large distances to the carbon centers, these water protons do not contribute to the cross-polarization. CCDC 1990182-1990183 contains the supplementary crystallographic data for this communication. These data can be obtained free of charge via http://www.ccdc.cam.ac.uk/conts/retrieving.html (or from the Cambridge Crystallographic Data Centre, 12, Union Road, Cambridge CB2 1EZ, UK; fax: +44 1223 336033). Most important crystallographic data are summarised in Table S1. 
Table S1. Crystallographic data and structure refinement details of compounds 1-L and 1-D.

\begin{tabular}{|c|c|c|}
\hline & 1-L & 1-D \\
\hline Empirical formula & $\mathrm{C}_{12} \mathrm{H}_{24} \mathrm{O}_{24} \mathrm{Y}_{2}$ & $\mathrm{C}_{12} \mathrm{H}_{22} \mathrm{O}_{23} \mathrm{Y}_{2}$ \\
\hline Formula weight & 730.13 & 712.11 \\
\hline Crystal system & triclinic & triclinic \\
\hline Space group & $P 1$ & $P 1$ \\
\hline$a(\AA)$ & $5.9865(2)$ & $5.9720(2)$ \\
\hline$b(\AA)$ & $7.3445(2)$ & $7.3806(2)$ \\
\hline$c(\AA)$ & $13.3124(4)$ & $13.0904(5)$ \\
\hline$\alpha\left(^{\circ}\right)$ & $102.369(3)$ & $102.517(3)$ \\
\hline$\beta\left(^{\circ}\right)$ & $101.979(3)$ & $101.411(3)$ \\
\hline$\gamma\left({ }^{\circ}\right)$ & $90.280(3)$ & $90.915(3)$ \\
\hline $\mathrm{V}\left(\AA^{3}\right)$ & $558.53(3)$ & $551.09(4)$ \\
\hline $\mathrm{Z}$ & 1 & 1 \\
\hline$\mu\left(\mathrm{mm}^{-1}\right)$ & 8.055 & 8.108 \\
\hline$\rho\left(\mathrm{g} \mathrm{cm}^{-3}\right)$ & 2.171 & 2.146 \\
\hline Crystal size (mm3) & $0.26 \times 0.22 \times 0.07$ & $0.37 \times 0.24 \times 0.19$ \\
\hline $\mathrm{F}(000)$ & 366 & 356 \\
\hline Unique reflections / total & $4320 / 19771$ & $4141 / 16023$ \\
\hline GOF & 1.067 & 1.062 \\
\hline Rint & 0.0694 & 0.0548 \\
\hline \multicolumn{3}{|l|}{ Final $\mathrm{R}$ indices } \\
\hline $\mathrm{R}_{1}^{\mathrm{a}} / \mathrm{wR}^{2 \mathrm{~b}}[\mathrm{I}>2 \sigma(\mathrm{I})]$ & $0.0391 / 0.1019$ & $0.0460 / 0.0461$ \\
\hline $\mathrm{R}_{1}^{\mathrm{a}} / \mathrm{wR}^{2 \mathrm{~b}}$ (all data) & $0.0391 / 0.1020$ & $0.1201 / 0.1201$ \\
\hline
\end{tabular}

${ }^{[a]} \mathrm{S}=\left[\sum \mathrm{w}\left(\mathrm{F}_{0}{ }^{2}-\mathrm{F}_{\mathrm{c}}{ }^{2}\right)^{2} /\left(\mathrm{N}_{\mathrm{obs}}-\mathrm{N}_{\mathrm{param}}\right)\right]^{1 / 2} \cdot{ }^{[\mathrm{b}]} \mathrm{R}_{1}=\sum|| \mathrm{F}_{0}|-| \mathrm{F}_{\mathrm{c}}|| / \sum\left|\mathrm{F}_{0}\right| \cdot{ }^{[\mathrm{c}]} \mathrm{wR}^{2}=\left[\sum \mathrm{w}\left(\mathrm{F}_{0}{ }^{2}-\mathrm{F}_{\mathrm{c}}{ }^{2}\right)^{2} / \sum \mathrm{wF}_{0}{ }^{2}\right]^{1 / 2} ; \mathrm{w}$ $=1 /\left[\sigma^{2}\left(\mathrm{~F}_{0}^{2}\right)+(\mathrm{aP})^{2}\right]$ where $\mathrm{P}=\left(\max \left(\mathrm{F}_{0}^{2}, 0\right)+2 \mathrm{~F}_{\mathrm{c}}^{2}\right) / 3 . \mathrm{a}=0.0905(\mathbf{1}-\mathbf{L})$ and $0.1071(\mathbf{1 - D}) ; \mathrm{b}=0.2054(\mathbf{1}-\mathbf{L})$ and 0.8742 (1-D). 
Table S2. Selected bond lengths for compound 1-L and 1-D. ${ }^{\mathrm{a}}$

\section{Compound 1-L}

\begin{tabular}{|c|c|c|c|}
\hline Y1-O11A & $2.480(5)$ & Y2-O41A(iii) & $2.333(6)$ \\
\hline $\mathrm{Y} 1-\mathrm{O} 12 \mathrm{~A}$ & $2.452(5)$ & Y2-O42A(iii) & $2.876(7)$ \\
\hline Y1-O12B & $2.340(5)$ & Y2-O11B & $2.309(5)$ \\
\hline Y1-O31B(i) & $2.468(5)$ & Y2-O21B & $2.565(5)$ \\
\hline Y1-O41B(i) & $2.361(6)$ & Y2-O12C(iv) & $2.340(5)$ \\
\hline Y1-O42B(ii) & $2.322(5)$ & $\mathrm{Y} 2-\mathrm{O} 31 \mathrm{C}$ & $2.478(5)$ \\
\hline $\mathrm{Y} 1-\mathrm{O} 11 \mathrm{C}$ & $2.334(5)$ & Y2-O41C & $2.366(6)$ \\
\hline $\mathrm{Y} 1-\mathrm{O} 21 \mathrm{C}$ & $2.583(5)$ & $\mathrm{Y} 2-\mathrm{O} 42 \mathrm{C}(\mathrm{v})$ & $1.963(4)$ \\
\hline Y1-O1w & $2.368(5)$ & $\mathrm{Y} 2-\mathrm{O} 2 \mathrm{w}$ & $2.338(5)$ \\
\hline \multicolumn{4}{|l|}{ Compound 1-D } \\
\hline Y1-O11A & $2.480(5)$ & Y2-O41A(viii) & $2.333(6)$ \\
\hline $\mathrm{Y} 1-\mathrm{O} 12 \mathrm{~A}$ & $2.452(5)$ & Y2-O42A(viii) & $2.876(7)$ \\
\hline Y1-O12B & $2.340(5)$ & Y2-O11B & $2.309(5)$ \\
\hline Y1-O31B(vi) & $2.468(5)$ & Y2-O21B & $2.565(5)$ \\
\hline Y1-O41B(vi) & $2.361(6)$ & Y2-O12C(ix) & $2.340(5)$ \\
\hline Y1-O42B(vii) & $2.322(5)$ & $\mathrm{Y} 2-\mathrm{O} 31 \mathrm{C}$ & $2.478(5)$ \\
\hline $\mathrm{Y} 1-\mathrm{O} 11 \mathrm{C}$ & $2.334(5)$ & $\mathrm{Y} 2-\mathrm{O} 41 \mathrm{C}$ & $2.366(6)$ \\
\hline $\mathrm{Y} 1-\mathrm{O} 21 \mathrm{C}$ & $2.583(5)$ & $\mathrm{Y} 2-\mathrm{O} 42 \mathrm{C}(\mathrm{x})$ & $1.963(4)$ \\
\hline Y1-O1w & $2.368(5)$ & $\mathrm{Y} 2-\mathrm{O} 2 \mathrm{w}$ & $2.338(5)$ \\
\hline
\end{tabular}

[a] Symmetries: (i) $\mathrm{x}, \mathrm{y}+1, \mathrm{z}$; (ii) $\mathrm{x}-1, \mathrm{y}+1$, $\mathrm{z}$; (iii) $\mathrm{x}-1, \mathrm{y}-1, \mathrm{z}-1$; (iv) $\mathrm{x}, \mathrm{y}-1, \mathrm{z}$; (v) $\mathrm{x}+1, \mathrm{y}, \mathrm{z}$; (vi) $\mathrm{x}, \mathrm{y}-1, \mathrm{z}$; (vii) $\mathrm{x}+1, \mathrm{y}-1, \mathrm{z}$; (viii) $\mathrm{x}+1, \mathrm{y}+1, \mathrm{z}+1$; (ix) $\mathrm{x}, \mathrm{y}+1, \mathrm{z}$; (x) $\mathrm{x}-1, \mathrm{y}, \mathrm{z}$. 
Table S3. Hydrogen bonding interactions $\left(\AA{ }^{\circ}{ }^{\circ}\right)$ of compound 1-L. ${ }^{a}$

\begin{tabular}{|c|c|c|c|c|}
\hline$D-H \cdots A^{b}$ & $D-H$ & $H^{\cdots} A$ & $D \cdots A$ & $D-H^{\cdots} A$ \\
\hline $\mathrm{O} 21 \mathrm{~A}-\mathrm{H} 21 \mathrm{~A} \cdots \mathrm{O} 42 \mathrm{~A}(\mathrm{i})$ & 0.85 & 1.94 & $2.792(8)$ & 172.5 \\
\hline O31A-H31A ‥O12A(ii) & 0.85 & 1.91 & $2.729(8)$ & 163.5 \\
\hline O21B-H21B ‥O11C(iii) & 0.86 & 1.74 & $2.583(8)$ & 167.5 \\
\hline O31B-H31B $\cdots \mathrm{O} 3 \mathrm{w}$ & 0.85 & 1.89 & $2.716(7)$ & 163.3 \\
\hline $\mathrm{O} 21 \mathrm{C}-\mathrm{H} 21 \mathrm{C} \cdots \mathrm{O} 11 \mathrm{~B}$ & 0.86 & 1.74 & $2.584(8)$ & 167.6 \\
\hline $\mathrm{O} 31 \mathrm{C}-\mathrm{H} 31 \mathrm{C} \cdots \mathrm{O} 4 \mathrm{w}$ & 0.84 & 1.99 & $2.754(8)$ & 149.6 \\
\hline $\mathrm{O} 1 \mathrm{w}-\mathrm{H} 11 \mathrm{w} \cdots \mathrm{O} 6 \mathrm{w}$ & 0.85 & 2.01 & $2.851(8)$ & 166.4 \\
\hline $\mathrm{O} 1 \mathrm{w}-\mathrm{H} 12 \mathrm{w} \cdots \mathrm{O} 41 \mathrm{~B}(\mathrm{iv})$ & 0.86 & 1.86 & $2.703(8)$ & 165.1 \\
\hline $\mathrm{O} 2 \mathrm{w}-\mathrm{H} 21 \mathrm{w} \cdots \mathrm{O} 5 \mathrm{w}$ & 0.86 & 1.89 & $2.727(8)$ & 164.3 \\
\hline $\mathrm{O} 2 \mathrm{w}-\mathrm{H} 22 \mathrm{w} \cdots \mathrm{O} 41 \mathrm{~B}(\mathrm{ii})$ & 0.86 & 1.90 & $2.72(8)$ & 157.5 \\
\hline $\mathrm{O} 3 \mathrm{w}-\mathrm{H} 31 \mathrm{w} \cdots \mathrm{O} 21 \mathrm{~A}(\mathrm{iii})$ & 0.86 & 2.04 & $2.852(8)$ & 157.4 \\
\hline $\mathrm{O} 3 \mathrm{w}-\mathrm{H} 32 \mathrm{w} \cdots \mathrm{O} 11 \mathrm{~A}$ & 0.86 & 1.98 & $2.802(8)$ & 159.8 \\
\hline $\mathrm{O} 4 \mathrm{w}-\mathrm{H} 41 \mathrm{w} \cdots \mathrm{O} 41 \mathrm{~A}(\mathrm{v})$ & 0.85 & 1.92 & $2.772(9)$ & 177.0 \\
\hline $\mathrm{O} 4 \mathrm{w}-\mathrm{H} 42 \mathrm{w} \cdot \mathrm{O}$ O6w(vi) & 0.85 & 1.94 & $2.792(8)$ & 173.1 \\
\hline O5w-H51w $\cdots$ O4w(vii) & 0.85 & 1.98 & $2.821(10)$ & 170.5 \\
\hline O5w-H52w...O6w(vi) & 0.85 & 2.45 & $3.286(9)$ & 169.3 \\
\hline O6w-H61w $\cdots$ O31A(viii) & 0.87 & 1.96 & $2.802(9)$ & 162.4 \\
\hline $\mathrm{O} 6 \mathrm{w}-\mathrm{H} 62 \mathrm{w} \cdots \mathrm{O} 11 \mathrm{~A}$ & 0.86 & 1.95 & $2.801(9)$ & 172.8 \\
\hline
\end{tabular}


Table S4. Hydrogen bonding interactions $\left(\AA,^{\circ}\right)$ of compound 1-D..$^{\text {a }}$

\begin{tabular}{|c|c|c|c|c|}
\hline$D-H \cdots A^{b}$ & $D-H$ & $H \cdots A$ & $D \cdots A$ & $D-H \cdots A$ \\
\hline $\mathrm{O} 21 \mathrm{~A}-\mathrm{H} 21 \mathrm{~A} \cdots \mathrm{O} 42 \mathrm{~A}(\mathrm{i})$ & 0.83 & 1.97 & $2.806(9)$ & 174.5 \\
\hline O31A-H31A $\cdots$ O12A(ii) & 0.86 & 1.89 & $2.720(9)$ & 162.2 \\
\hline O21B-H21B $\cdots$ O11C(iii) & 0.84 & 1.76 & $2.602(9)$ & 174.3 \\
\hline $\mathrm{O} 31 \mathrm{~B}-\mathrm{H} 31 \mathrm{~B} \cdots \mathrm{O} 3 \mathrm{w}$ & 0.85 & 1.93 & $2.750(9)$ & 162.2 \\
\hline $\mathrm{O} 21 \mathrm{C}-\mathrm{H} 21 \mathrm{C} \cdots \mathrm{O} 11 \mathrm{~B}$ & 0.87 & 1.77 & $2.595(9)$ & 158.3 \\
\hline $\mathrm{O} 31 \mathrm{C}-\mathrm{H} 31 \mathrm{C} \cdots \mathrm{O} 4 \mathrm{w}$ & 0.85 & 1.81 & $2.645(9)$ & 168.6 \\
\hline $\mathrm{O} 1 \mathrm{w}-\mathrm{H} 11 \mathrm{w} \cdots \mathrm{O} 5 \mathrm{w}$ & 0.85 & 2.02 & $2.854(9)$ & 165.5 \\
\hline $\mathrm{O} 1 \mathrm{w}-\mathrm{H} 12 \mathrm{w} \cdots \mathrm{O} 41 \mathrm{~B}(\mathrm{iv})$ & 0.85 & 1.90 & $2.726(9)$ & 161.7 \\
\hline $\mathrm{O} 2 \mathrm{w}-\mathrm{H} 21 \mathrm{w} \cdots \mathrm{O} 4 \mathrm{w}(\mathrm{iii})$ & 0.85 & 2.17 & $2.809(10)$ & 131.9 \\
\hline $\mathrm{O} 2 \mathrm{w}-\mathrm{H} 22 \mathrm{w} \cdots \mathrm{O} 41 \mathrm{C}(\mathrm{ii})$ & 0.85 & 2.05 & $2.705(9)$ & 133.3 \\
\hline $\mathrm{O} 3 \mathrm{w}-\mathrm{H} 31 \mathrm{w} \cdots \mathrm{O} 21 \mathrm{~A}(\mathrm{iii})$ & 0.84 & 2.10 & $2.819(9)$ & 143.7 \\
\hline $\mathrm{O} 3 \mathrm{w}-\mathrm{H} 32 \mathrm{w} \cdots \mathrm{O} 11 \mathrm{~A}$ & 0.85 & 1.99 & $2.798(9)$ & 159.2 \\
\hline $\mathrm{O} 4 \mathrm{w}-\mathrm{H} 41 \mathrm{w} \cdots \mathrm{O} 41 \mathrm{~A}(\mathrm{v})$ & 0.86 & 1.89 & $2.729(11)$ & 162.5 \\
\hline $\mathrm{O} 4 \mathrm{w}-\mathrm{H} 42 \mathrm{w} \cdots \mathrm{O} 5 \mathrm{w}(\mathrm{vi})$ & 0.85 & 2.03 & $2.868(10)$ & 170.9 \\
\hline O5w-H51w $\cdots O 31 \mathrm{O}(\mathrm{vii})$ & 0.85 & 2.10 & $2.828(9)$ & 143.7 \\
\hline $\mathrm{O} 5 \mathrm{w}-\mathrm{H} 52 \mathrm{w} \cdots \mathrm{O} 3 \mathrm{w}$ & 0.85 & 1.93 & $2.734(10)$ & 156.2 \\
\hline
\end{tabular}




\section{S3. Synthesis of compounds 1-L and 1-D.}

$5 \mathrm{~mL}$ of an aqueous solution containing $0.6 \mathrm{mmol}$ of $\mathrm{Y}\left(\mathrm{NO}_{3}\right)_{3} \cdot 6 \mathrm{H}_{2} \mathrm{O}(0.2298 \mathrm{~g})$ were added dropwise over an aqueous solution $(5 \mathrm{~mL})$ of the corresponding tartaric acid $\left(\mathrm{H}_{2}\right.$-TAR-L/D, $\left.0.9 \mathrm{mmol}, 0.1351 \mathrm{~g}\right)$ under continuous stirring. The resulting solution was heated in a Teflon-line autoclave at $140{ }^{\circ} \mathrm{C}$ for $48 \mathrm{~h}$ and slowly cooled down to room temperature. Compounds 1-L and 1-D with $\left\{\left[\mathrm{Y}_{2}\left(\mu_{4}-\mathrm{TAR}-\mathrm{L}\right)_{2}(\mu-\operatorname{tar}-\right.\right.$ $\left.\left.\mathrm{L})\left(\mathrm{H}_{2} \mathrm{O}\right)_{2}\right] \cdot 4 \mathrm{H}_{2} \mathrm{O}\right\}_{\mathrm{n}}$ and $\left\{\left[\mathrm{Y}_{2}\left(\mu_{4}-\mathrm{TAR}-\mathrm{D}\right)_{2}(\mu-\operatorname{tar}-\mathrm{D})\left(\mathrm{H}_{2} \mathrm{O}\right)_{2}\right] \cdot 3 \mathrm{H}_{2} \mathrm{O}\right\}_{\mathrm{n}}$ formulae, respectively, are purely obtained. Elemental analyses for $\mathrm{C}_{12} \mathrm{H}_{24} \mathrm{O}_{24} \mathrm{Y}_{2}(\mathbf{1}-\mathbf{L})\left(730.13 \mathrm{~g} \mathrm{~mol}^{-1}\right)$. Calcd.: C, 19.74; H, 3.31; Y, 24.35. Found: C, 19.96; H, 3.25; Y, 24.26. Elemental analysis for $\mathrm{C}_{12} \mathrm{H}_{22} \mathrm{O}_{23} \mathrm{Y}_{2}$ (1-D) (712.11 $\mathrm{g} \mathrm{mol}^{-1}$ ). Calcd.: C, 20.24; H, 3.11; Y, 24.97. Found: C, 20.53; H, 3.05; Y, 24.68. 


\section{S4. Thermogravimetric Analyses.}

The thermogravimetric behaviour of both compounds is similar and starts with a short plateau in the TG curve from room temperature up to ca. $70^{\circ} \mathrm{C}$, after which the lattice water molecules present in the channels of the compound are lost. The mass loss accounts for the release of four (1-L) or three (1-D) crystallization water molecules in agreement with the crystal structures. Then, after a small plateau of $40{ }^{\circ} \mathrm{C}$, materials experiment the loss of two coordination water molecules, which finishes at ca. $200{ }^{\circ} \mathrm{C}$ and yields a dehydrated phase of the compound that shows no mass loss up to $270{ }^{\circ} \mathrm{C}$. Above the latter temperature, compounds 1-L and 1-D experiment several exothermic processes as a consequence of the decomposition of the organic part, leading to $\mathrm{Y}_{2} \mathrm{O}_{3}$ as a final residue.
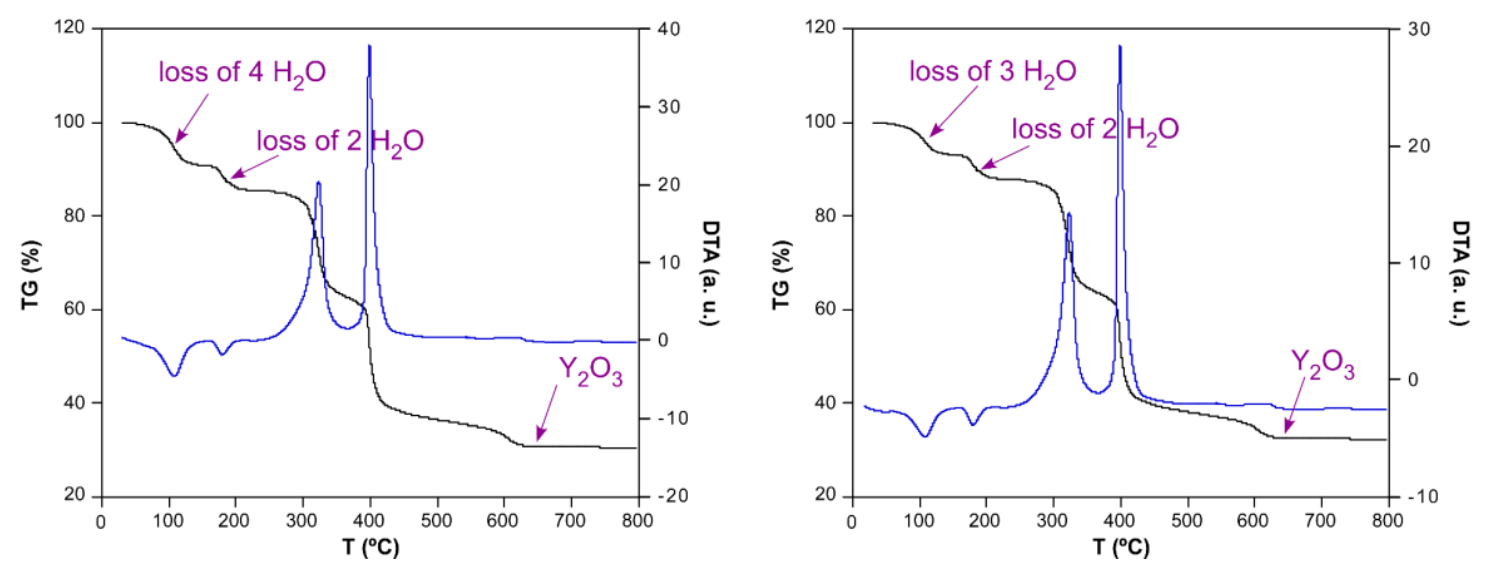

Figure S1. TG/DTA analyses for compounds 1-L (left) and 1-D (right). 


\section{S5. Powder X-ray Diffraction Analysis.}

X-ray powder diffraction (XRPD) pattern was collected on a Phillips X'PERT powder diffractometer with $\mathrm{Cu}-\mathrm{K} \alpha$ radiation $(\lambda=1.54060 \AA)$ over the $5<2 \theta<50^{\circ}$ range with a step size of $0.026^{\circ}$ and an acquisition time of $2.5 \mathrm{~s}$ per step at $25^{\circ} \mathrm{C}$. Indexation of the diffraction profiles were made by means of the FULLPROF program (pattern-matching analysis) on the basis of the space group and the cell parameters found for the $\mathrm{X}$-ray single crystal structures.

Pattern-matching analysis confirms the purity of the polycrystalline samples of 1-L and 1-D.

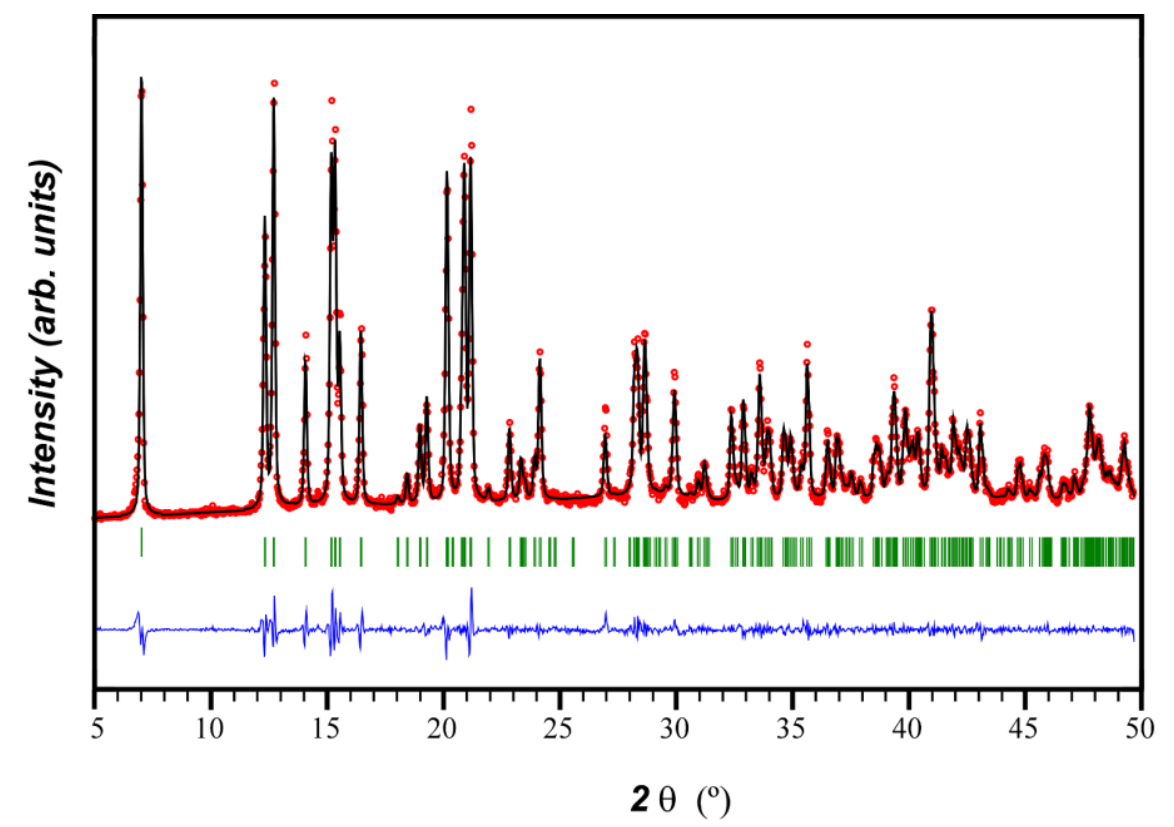

Figure S2. Pattern-matching analysis of polycrystalline sample of compound 1-L. 


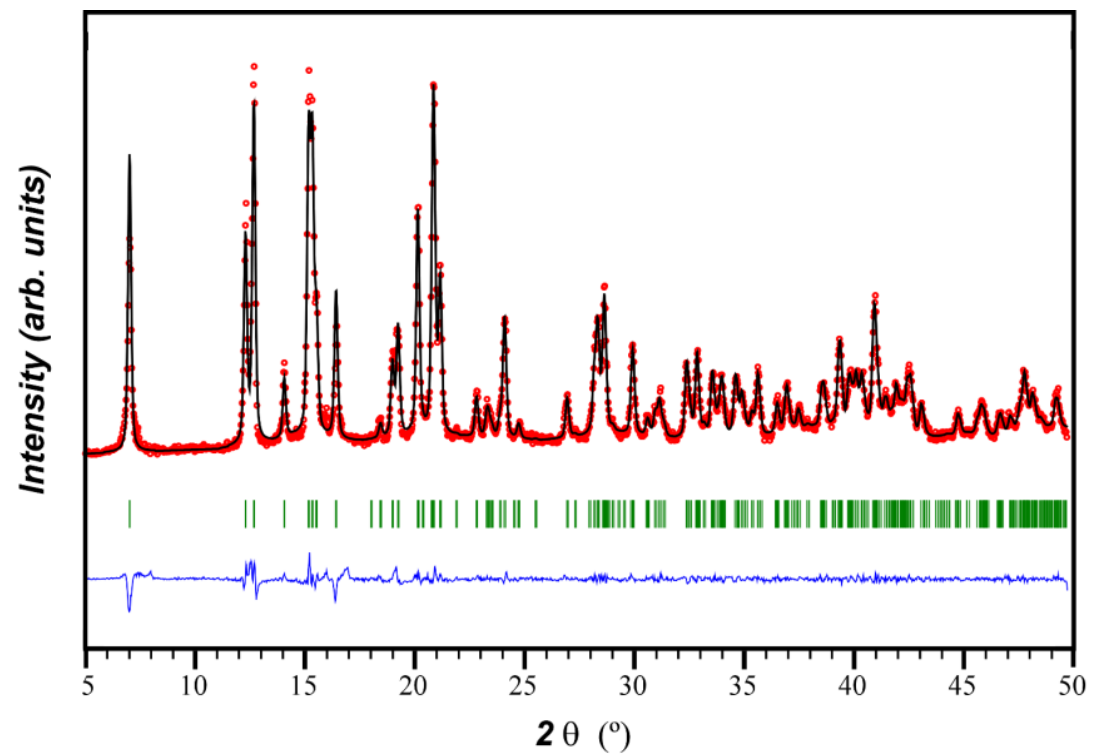

Figure S3. Pattern-matching analysis of polycrystalline sample of compound 1-D.

PXRD analyses of the free ligands has been also performed, allowing us determining not only its chemical formulae but also its crystal structure. Powdered samples of free ligands correspond to pure tartaric acid crystallized as the enantiomerically pure structure $\left(\mathrm{H}_{2}\right.$-TTA) without solvent molecules co-crystallized. The crystal structures consist of hydrogen-bonded molecules as found in TARTAC $\left(\mathrm{H}_{2}\right.$-TAR-D) and TARTAL $\left(\mathrm{H}_{2}\right.$-TAR-L) cif files deposited with the CCDC database.

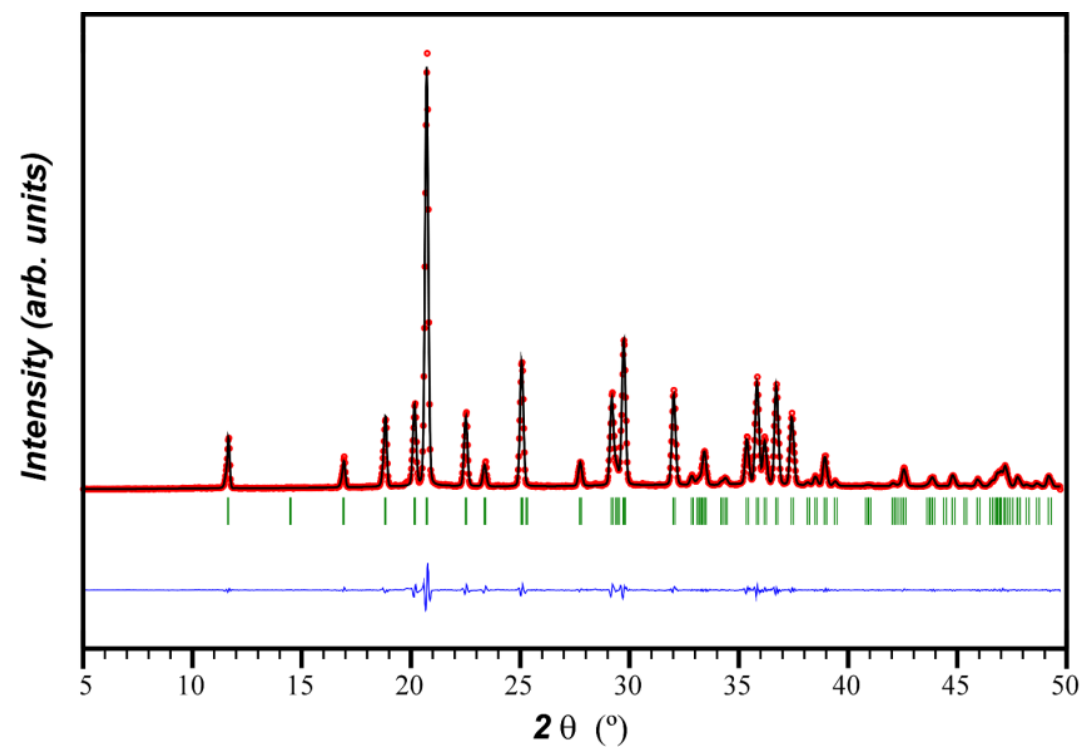

Figure S4. Pattern-matching analysis of polycrystalline sample of $\mathrm{H}_{2}$-TAR-L ligand. 


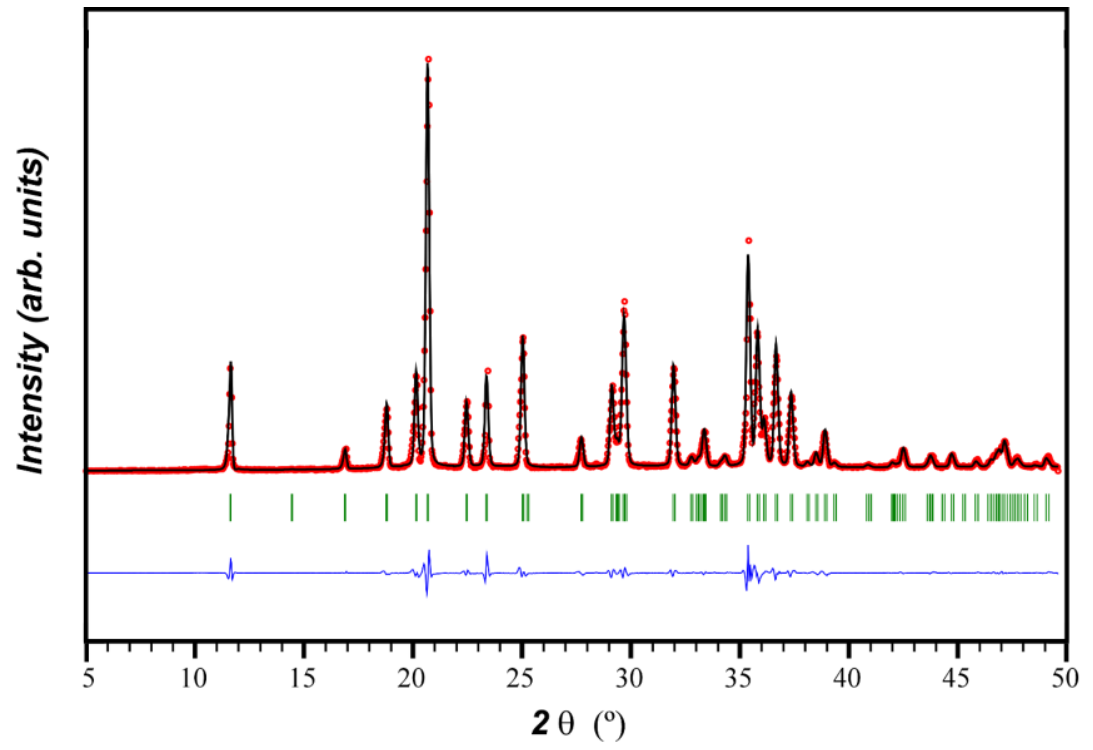

Figure S5. Pattern-matching analysis of polycrystalline sample of $\mathrm{H}_{2}$-TAR-D ligand. 


\section{S6. FT-IR spectroscopy.}

Compounds 1-L and 1-D share almost identical FTIR spectra where, at high frequencies, all compounds exhibit an intense band around $3600 \mathrm{~cm}^{-1}$ that corresponds to the vibration of $\mathrm{O}-\mathrm{H}$ bond of water. Between 3500 and $2900 \mathrm{~cm}^{-1}$ stretching bands of the alcoholic $\mathrm{O}-\mathrm{H}$ bond are appeared. Weak shoulders between 2850 and $2400 \mathrm{~cm}^{-1}$ are attributed to $\mathrm{C}-\mathrm{H}$ stretching vibrations of the tartrate ligand. The intense vibrations around $1610 \mathrm{~cm}^{-1}$ correspond to the asymmetric stretching vibration of carboxylate groups, while the symmetric stretching and bending of the same group occur in the lower range of $1500-1400 \mathrm{~cm}^{-1}$. Bands associated with bending vibrations of the $\mathrm{C}-\mathrm{H}$ bonds are observed around $1320 \mathrm{~cm}^{-1}$, followed by bending bands of the alcoholic O-H groups between 1300 and $1200 \mathrm{~cm}^{-1}$. Stretching of C-O bond of the secondary alcohols occurs in the range of $1150-1000 \mathrm{~cm}^{-1}$. Different bands at the range of $950-800 \mathrm{~cm}^{-1}$ are attributed to trisubstituted $\mathrm{C}-\mathrm{H}$ bending vibrations. The vibration bands of the $\mathrm{Y}-\mathrm{O}$ coordination bonds are observed in the less energetic $605-400 \mathrm{~cm}^{-1}$ range.

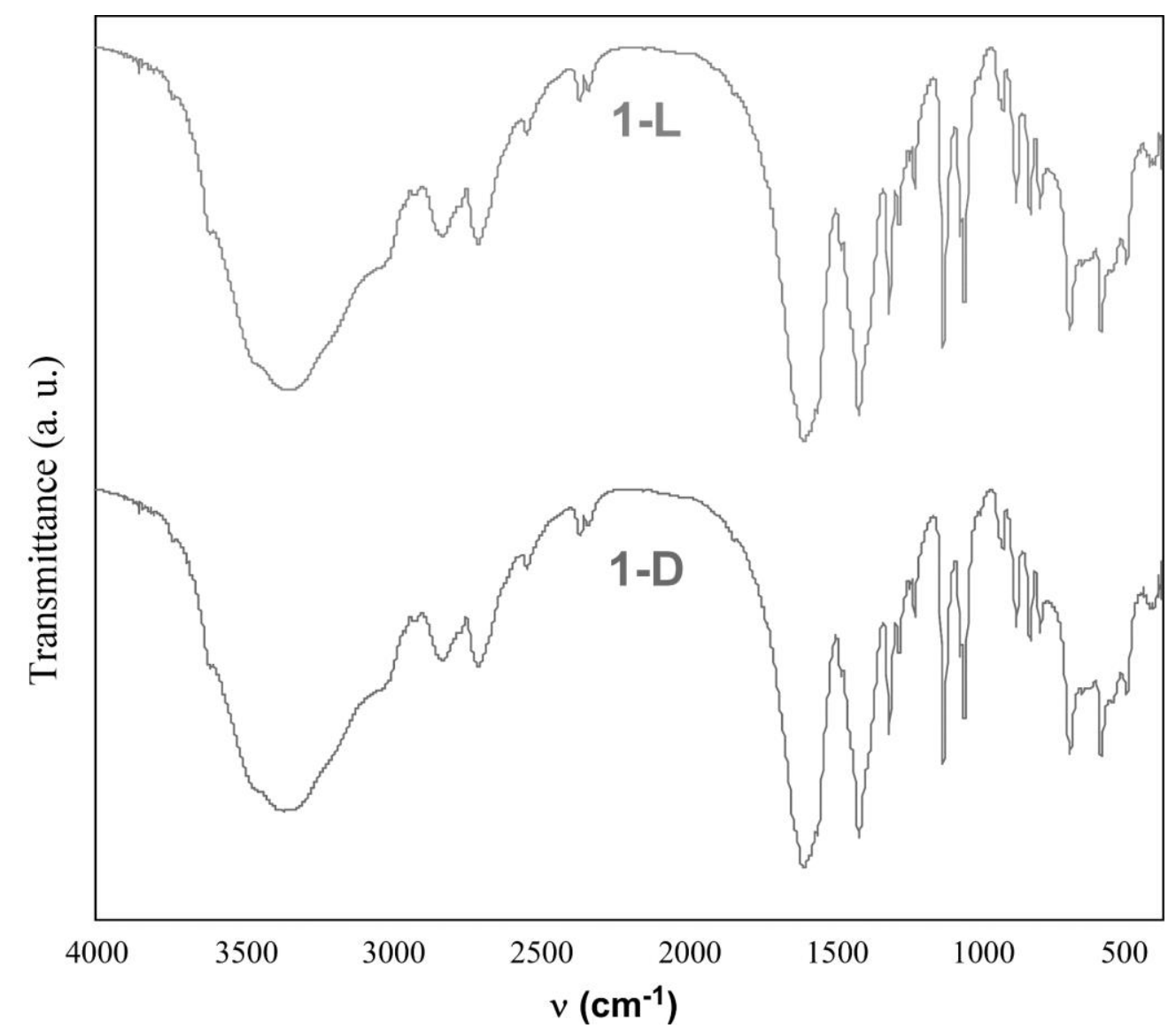

Figure S6. FTIR spectra of compounds 1-L (top) and 1-D (bottom). 


\section{S7. Topological analysis.}

Crystal structure of 1-L and 1-D compounds consists of a 3D network built up from the linkage of two symmetrically independent nona-coordinated yttrium(III) centres by means of three independent tartrate ligands, which in turn show two distinct coordination modes: two of them with $\mu_{4^{-}}$ $\kappa O: \kappa^{2} \mathrm{O}^{\prime}, \mathrm{O}^{\prime \prime}: \kappa^{2} \mathrm{O}^{\prime \prime}, \mathrm{O}^{\prime \prime \prime}: \kappa \mathrm{O}^{\prime \prime \prime \prime}$ and the other with $\mu-\kappa^{2} \mathrm{O}, \mathrm{O}^{\prime}: \kappa^{2} \mathrm{O}^{\prime \prime}, \mathrm{O}^{\prime \prime \prime}$ mode. As a result, both metal centres and ligands may be considered as nodes of the topological network (except for the linear $\mu$-tartrate connectors), so it can be simplified as a two-nodal net (with a 4-connected and a 5-connected node) with the fsx topology that possesses the $\left(4^{2} .6^{4}\right)\left(4^{2} .6^{7} .8\right)$ point symbol.
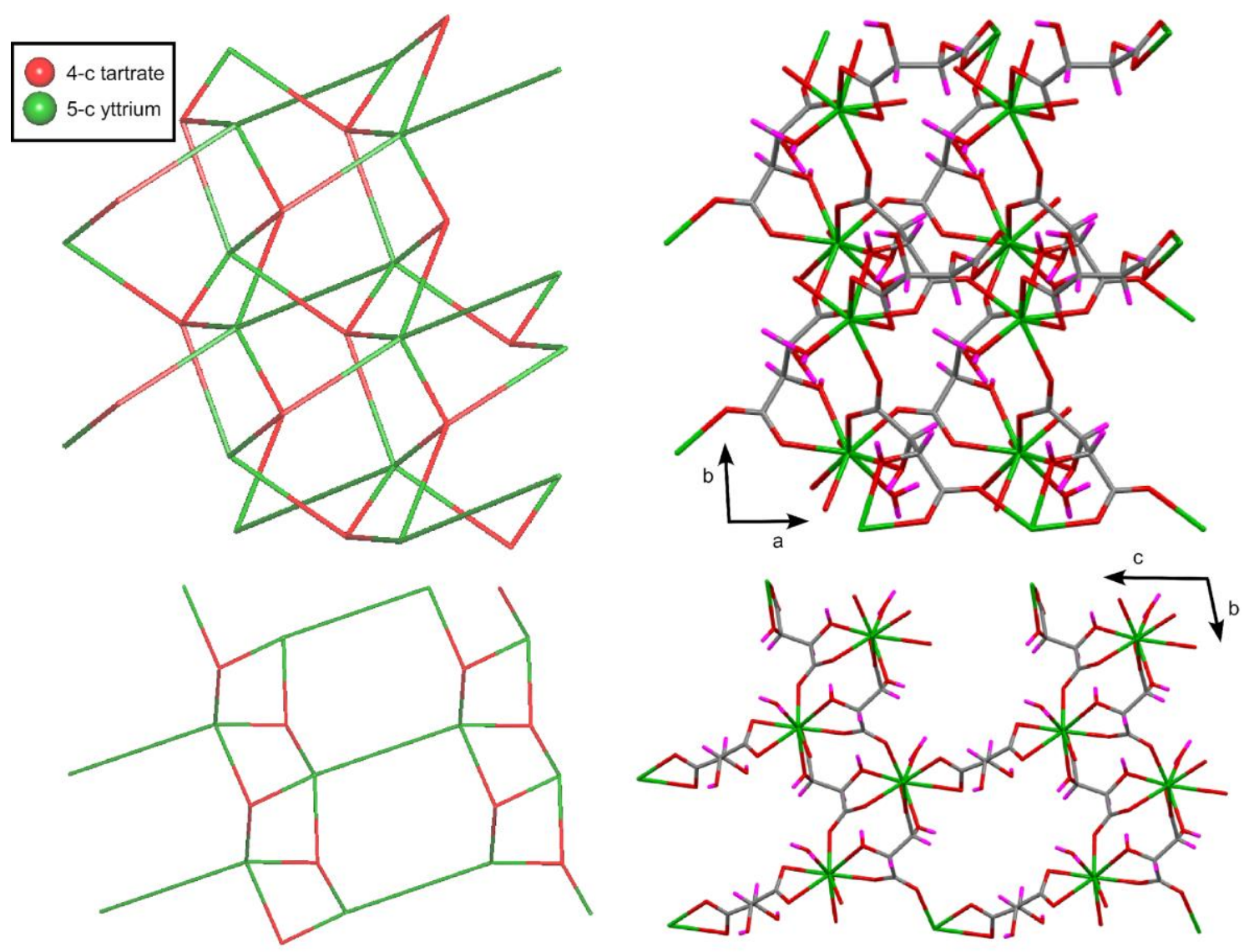

Figure S7. Views of the topological (left) and molecular (right) networks of compound 1-L. 


\section{S8. UVA-Vis and CD spectra of 1-L and 1-D.}

UVA-Vis and Circular dichroism (CD) spectra were recorded at $25^{\circ} \mathrm{C}$ on a Jasco J-815 spectropolarimeter, using $1 \mathrm{~cm}$ path-length cuvettes and the following parameters: sensitivity $100 \mathrm{mdeg}$; data pitch $0.5 \mathrm{~nm}$; scanning speed $200 \mathrm{~nm} / \mathrm{min}$; response 0.5 or $1 \mathrm{sec}$; band width $1 \mathrm{~nm}$. MilliQ water suspensions (4 mg + 2 $\mathrm{ml}$ solvent) of 1-L and 1-D were sonicated for $2 \mathrm{~h}$ prior to measuring the CD and UVA-Vis spectra.

UVA-Vis spectrum of 1-L and 1-D revealed one intense maxima centered at $187 \mathrm{~nm}$, potentially corresponding to $\mathrm{n} \rightarrow \mathrm{pi}^{*}$ intraligand electron transfer processes, and a secondary maxima, revealed as a shoulder in the region at 200-240 nm. UVA-Vis spectrum of L-tar and D-tar samples revealed the same pattern.
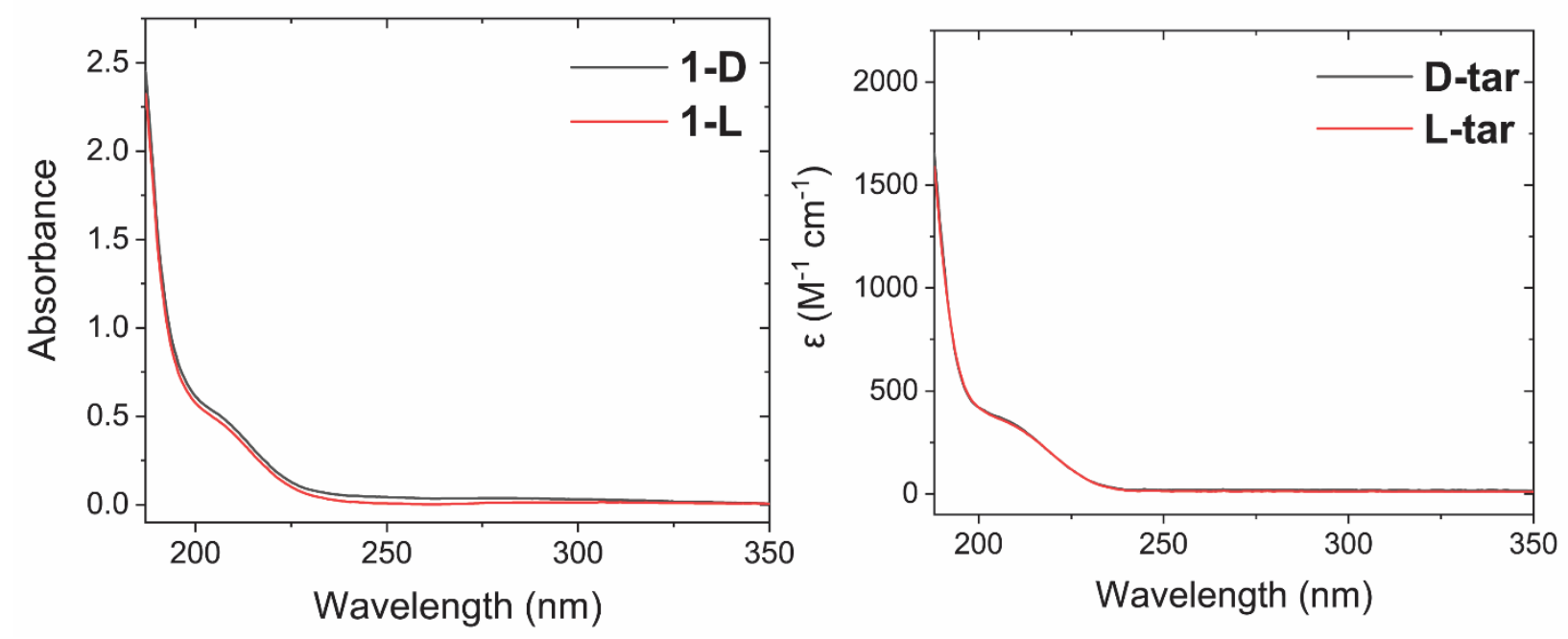

Figure S8. UVA-Vis spectrum of water saturated solutions of compounds 1-L and 1-D (left panel) and of the ligands TAR-L- and TAR-D (right panel). 


\section{S9. Experimental NMR part and statistical analysis.}

\section{General procedure:}

All solid-state NMR experiments were performed with a widebore 9.4 T NMR spectrometer equipped with a Bruker Avance III HD console and a $4.0 \mathrm{~mm}$ DVT double resonance HX MAS probe. For all NMR experiments, $95.0 \mathrm{mg}$ of material was packed into a $4 \mathrm{~mm}$ rotor. The MAS rate was set to $10 \mathrm{kHz}$. Larmor frequencies were $400.17 \mathrm{MHz}$ and $100.63 \mathrm{MHz}$ for ${ }^{1} \mathrm{H}$ and ${ }^{13} \mathrm{C}$ nuclei, respectively.

The recycle delay values to be used in the latter type of experiments were carefully chosen and set to five times the largest spin-lattice relaxation time (T1), approximately. This selection of acquisition parameters, ensures a complete relaxation of all nuclei and therefore definitely rules out the possibility that the observed differences in signal intensities arise from signal saturation effects due to too short recycle delays. With that goal in mind, T1 $\left({ }^{1} \mathrm{H}\right)$ were measured both in DP and CP experiments for our samples, by means of a saturation recovery experiment, within TOPSPIN NMR software, and $\mathrm{T} 1\left({ }^{13} \mathrm{C}\right)$ in DP experiments were estimated by applying the $\mathrm{T} 1\left({ }^{13} \mathrm{C}\right) / \mathrm{T} 1\left({ }^{1} \mathrm{H}\right)$ ratio measured in an isotopically enriched glycine to our samples, whose $\mathrm{T} 1\left({ }^{1} \mathrm{H}\right)$ relaxation times were measured in $\mathrm{CP}$ conditions.

An appropriate spin-lock time was also selected among several tested. In this line, three alternative experiments with increasing spin-lock times were run and their influence on the $\mathrm{I}_{\mathrm{D}} / \mathrm{I}_{\mathrm{L}}$ intensity ratios analyzed.

\section{Measurement of $\mathrm{T1}\left({ }^{13} \mathrm{C}\right)$ and $\mathrm{T} 1\left({ }^{1} \mathrm{H}\right)$ in an isotopically enriched glycine.}

Figures $\mathrm{S} 8$ and $\mathrm{S} 9$ show the $\mathrm{T} 1\left({ }^{13} \mathrm{C}\right)$ and $\mathrm{T} 1\left({ }^{1} \mathrm{H}\right)$ saturation recovery experiments for the two groups of ${ }^{13} \mathrm{C}$ signals found in the spectrum of a ${ }^{13} \mathrm{C}$ enriched glycine sample. The $\mathrm{T} 1\left({ }^{13} \mathrm{C}\right)$ were found to be $7.089 \mathrm{~s}$ for the signals in the 192-163 ppm range, and 7.325s for the signals in the 52-24 ppm range, yielding an average value for $\mathrm{T} 1\left({ }^{13} \mathrm{C}\right)$ of $7.21 \mathrm{~s}$. Then, $\mathrm{T} 1\left({ }^{1} \mathrm{H}\right)$ values were measured by individually fitting the intensity of the ${ }^{13} \mathrm{C}$ NMR signals as a function of the saturation recovery delay, and were found to be 326.63 and $327.12 \mathrm{~ms}$ for both regions of spectrum, respectively, yielding an average T1 $\left({ }^{1} \mathrm{H}\right)$ value of $326.88 \mathrm{~ms}$. The $\mathrm{T} 1\left({ }^{13} \mathrm{C}\right) / \mathrm{T} 1\left({ }^{1} \mathrm{H}\right)$ ratio was therefore estimated to be 22.05 , in line with previously reported values. ${ }^{4}$ Presumably, these ratio should be smaller in our non-enriched samples, since $\mathrm{T} 1\left({ }^{13} \mathrm{C}\right)$, but particularly $\mathrm{T} 1\left({ }^{1} \mathrm{H}\right)$, are expected to be larger, due to the absence of large dipolar coupling effects. 
Measurement of T1 $\left({ }^{1} \mathrm{H}\right)$ in CP-MAS experiments and T1 $\left({ }^{13} \mathrm{C}\right)$ in DP-MAS experiments for 1-D and 1-L MOFs, and TAR-D and TAR-L ligands.

The T1 $\left({ }^{1} \mathrm{H}\right)$ of the five different ${ }^{13} \mathrm{C}$ (groups of) signals found in the 1-D and $\mathbf{1 - L}$ spectra, and the T1 $\left({ }^{1} \mathrm{H}\right.$ ) of the groups of signals found in four different regions on the spectra of TAR-D and TAR-L, were again measured by individually fitting the intensity of the ${ }^{13} \mathrm{C}$ NMR signals as a function of the saturation recovery delay. The obtained results are collected in Table S5 below and in Figures S10 to S13. For 1-L and 1-D samples, mean T1 $\left({ }^{1} \mathrm{H}\right)$ values were found to be $0.943 \mathrm{~s}$ and $1.275 \mathrm{~s}$ for $\mathbf{1 - D}$, respectively. For TAR-L and TAR-D samples, the mean $\mathrm{T} 1\left({ }^{1} \mathrm{H}\right)$ values were found to be ca. ten times as large as those found in 1-D and 1-L, with values of $94.90 \mathrm{~s}$ and $140.15 \mathrm{~s}$, respectively.

Table S5. Measured T1 $\left({ }^{1} \mathrm{H}\right)$ for each region/group of signals in the ${ }^{13} \mathrm{C}-\mathrm{CP}-\mathrm{MAS}-\mathrm{SS}-\mathrm{NMR}$ spectra acquired for 1-L and 1-D complexes, and TAR-L and TAR-D ligands, and their mean values, in seconds.

\begin{tabular}{|c|c|c|c|c|c|c|c|}
\hline \multicolumn{8}{|c|}{ T1 $\left({ }^{1} H\right)$ in seconds } \\
\hline & $\delta$ (ppm) & 1-L & 1-D & & $\delta(p p m)$ & TAR-L & TAR-D \\
\hline Region 1 & $186.5-184.8$ & 1.109 & 1.311 & Region 1 & $177.3-175.0$ & 92.94 & 145.8 \\
\hline Region 2 & $182.5-180.5$ & 0.903 & 1.214 & Region 2 & $172.7-170.1$ & 96.70 & 135.7 \\
\hline Region 3 & 179.9-176.1 & 0.733 & 1.277 & Region 3 & $75.9-73.3$ & 98.15 & 142.1 \\
\hline Region 4 & $77.4-74.5$ & 1.029 & 1.309 & Region 4 & $73.3-70.7$ & 91.80 & 137.0 \\
\hline \multirow[t]{2}{*}{ Region 5} & $74.5-72.5$ & 0.940 & 1.263 & - & - & - & - \\
\hline & Mean & 0.943 & 1.275 & Mean & & 94.90 & 140.15 \\
\hline
\end{tabular}

Considering the $\mathrm{T} 1\left({ }^{1} \mathrm{H}\right)$ values above, and the $\mathrm{T} 1\left({ }^{1} \mathrm{H}\right) / \mathrm{T} 1\left({ }^{13} \mathrm{C}\right)$ ratio of 22.05 found in an isotopically enriched glycine sample, the largest $\mathrm{T} 1\left({ }^{13} \mathrm{C}\right)$ values in our samples were estimated to be $20.79 \mathrm{~s}, 23.70 \mathrm{~s}$ for carbon nuclei in 1-L and 1-D samples, respectively, and as large as 2092.54 s and 2090.31 s for carbon nuclei in TAR-L and TAR-D samples, respectively.

In our $\mathrm{CP}$ experiments, where ${ }^{13} \mathrm{C}$ signal intensities of the $\mathrm{D}$ and $\mathrm{L}$ enantiomers are expected to differ, the recycle delay value (usually 5 times the largest relaxation time) was set to 6.5 s for experiments run on 1-L and 1-D samples, i.e. ca. 6.5 times the average T1 $\left({ }^{1} \mathrm{H}\right)$ value found. In the same line the recycle delay value was set to $650 \mathrm{~s}$ in the ${ }^{13} \mathrm{C}$ CP-MAS experiments run on TAR-L and TAR-D samples (a recycle delay of 460 s did not alter the relative intensity values; see Table S6 below).

In our DP experiments, where ${ }^{13} \mathrm{C}$ signal intensities of the $\mathrm{D}$ and $\mathrm{L}$ enantiomers are expected to be the same, the recycle delay values were set to ca. 5 times the average $\mathrm{T} 1\left({ }^{13} \mathrm{C}\right)$ values, i.e. a recycle delay of $60 \mathrm{~s}$ for the ${ }^{13} \mathrm{C}$ DP-MAS experiments run on 1-L and 1-D samples, and $14000 \mathrm{~s}$ for the ${ }^{13} \mathrm{C}$ DP-MAS experiments run on TAR-L and TAR-D samples, respectively. 
It is equally important to note that, an appropriate spin-lock time was selected among several tested. In this line, different experiments $(\mathrm{n}=1)$ were run with $\mathbf{1 - L}$ and 1-D samples using contact times of 1, 2 and $4 \mathrm{~ms}$, respectively (Table S6). Importantly, the results revealed that 1-D ${ }^{13} \mathrm{C}$ signals' intensity was systematically larger than the 1-L ${ }^{13} \mathrm{C}$ signals' intensity, as derived from the $\mathrm{I}_{\mathrm{D}} / \mathrm{I}_{\mathrm{L}}$ peak intensity ratios in Table S6. Due to the large recycle delay values for the ligand samples, an intermediate value of a contact time of 2 ms was regarded as a good compromise in both samples.

Table S6: Calculated $\mathrm{I}_{\mathrm{D}} / \mathrm{I}_{\mathrm{L}}$ intensity ratios $(\mathrm{n}=1)$, for several spin lock (ms) and recycle delay (s) values of 1-L and 1-D complexes and TAR-L and TAR-D ligands.

\begin{tabular}{|c|c|c|c|c|c|c|}
\hline \multicolumn{7}{|c|}{${ }^{13} \mathrm{C}-\mathrm{CP}-\mathrm{MAS}-\mathrm{SS}-\mathrm{NMR}$} \\
\hline & & & \multicolumn{4}{|c|}{ Relative Intensity $\left(\mathrm{I}_{\mathrm{D}} / \mathrm{I}_{\mathrm{L}}\right)$} \\
\hline & & & \multicolumn{2}{|c|}{ Carboxylic C } & \multicolumn{2}{|c|}{ Aliphatic C } \\
\hline Sample & $\begin{array}{c}\text { spin-lock } \\
(\mathrm{ms})\end{array}$ & $\begin{array}{c}\text { recycle } \\
\text { delay (s) }\end{array}$ & \multicolumn{2}{|c|}{$\begin{array}{c}\delta \\
189-173 \mathrm{ppm}\end{array}$} & \multicolumn{2}{|c|}{$\begin{array}{c}\delta \\
80-69 \mathrm{ppm}\end{array}$} \\
\hline 1-D/1-L & 1 & 6.5 & \multicolumn{2}{|c|}{1.27} & \multicolumn{2}{|c|}{1.44} \\
\hline 1-D/1-L & 2 & 6.5 & \multicolumn{2}{|c|}{1.28} & \multicolumn{2}{|c|}{1.38} \\
\hline $1-\mathrm{D} / 1-\mathrm{L}$ & 4 & 6.5 & \multicolumn{2}{|c|}{1.48} & \multicolumn{2}{|c|}{1.43} \\
\hline & & & $\begin{array}{c}\delta \\
176.3 \mathrm{ppm}\end{array}$ & $\begin{array}{c}\delta \\
171.6 \mathrm{ppm}\end{array}$ & $\begin{array}{c}\delta \\
4.2 \mathrm{ppm}\end{array}$ & $\begin{array}{c}\delta \\
71.7 \mathrm{ppm}\end{array}$ \\
\hline TAR-D/TAR-L & 2 & 460 & 1.28 & 1.28 & 1.19 & 1.24 \\
\hline TAR-D/ TAR-L & 2 & 650 & 1.26 & 1.26 & 1.26 & 1.21 \\
\hline
\end{tabular}

Statistical analysis. Table S7-S12 collect integral values of each signal/group of signals measured in each sample, replicate $(n=3)$ and experimental conditions (CP and DP), together with the standard deviation and variance values. The statistical analysis is carried out by measuring three different spectra for each sample and experiment time under the optimized conditions, namely, spin-locks times of $2 \mathrm{~ms}$, combined with recycle delay of ca. $5 \mathrm{xT}_{1}\left({ }^{1} \mathrm{H}\right)$ in all experiments and samples, i.e. $6.5 \mathrm{~s}$ for the 1-L and 1-D complexes, and $650 \mathrm{~s}$ for the TAR-L and TAR-D compounds in the ${ }^{13} \mathrm{C}$ SS-CP-MAS spectra, and recycle delays of $60 \mathrm{~s}$ for the 1-L and 1-D compounds, and $14000 \mathrm{~s}$ for the TAR-L and TAR-D compound in the ${ }^{13} \mathrm{C}$ SS-DPMAS.

The latter values were then used to calculate the $\mathrm{I}_{\mathrm{D}} / \mathrm{I}_{\mathrm{L}}$ ratio $( \pm$ standard deviaton, sd), in order to check for statistical significance of the measured D-L difference. The sd was calculated according to the mathematical expression given below, 


$$
\frac{d R}{R}=\sqrt{\left(\frac{d D}{D}\right)^{2}+\left(\frac{d L}{L}\right)^{2}}
$$

being $\mathrm{D}$ and $\mathrm{L}$ the signal integral value for the $\mathrm{D}$ and $\mathrm{L}$ enantiomer, $\mathrm{R}$ their $\mathrm{I}_{\mathrm{D}} / \mathrm{I}_{\mathrm{L}}$ ratio, and $\mathrm{dL}, \mathrm{dD}$ and $\mathrm{dR}$ the standard deviations of the signals in either L or D enantiomers, and of their ratio, respectively. The calculated values are collected in Table 1 of the main text of manuscript. 
Table S7. Measured ${ }^{13} \mathrm{C}-\mathrm{CP}-\mathrm{MAS}$ signal areas for carboxylic and aliphatic $\mathrm{C}$ types in the 1-L and 1-D MOF, along with average values, standard deviations and variances.

\begin{tabular}{lcccc}
\hline \multicolumn{4}{c}{${ }^{13}$ C-SS-CP-MAS } \\
\hline & \multicolumn{2}{c}{ Carboxylic C } & \multicolumn{2}{c}{ Aliphatic C } \\
& 1-L & 1-D & 1-L & 1-D \\
& $\delta=189-173 \mathrm{ppm}$ & $\delta=189-173 \mathrm{ppm}$ & $\delta=80-69 \mathrm{ppm}$ & $\delta=80-69 \mathrm{ppm}$ \\
\hline Replicate 1 & 17875549.26 & 23157664.88 & 18263257.77 & 27238569.41 \\
Replicate 2 & 18172094.08 & 22998185.85 & 19026127.74 & 25685526.13 \\
Replicate 3 & 18359841.45 & 23453363.60 & 19346676.52 & 25221620.05 \\
\hline Mean & 18135828.26 & 23203071.44 & 18878686.00 & 26048571.90 \\
Standard Deviation & 244174.40 & 230961.06 & 556556.83 & 1056348.82 \\
Variance & $5.9610^{10}$ & $5.3310^{10}$ & $3.1010^{11}$ & $1.1210^{12}$ \\
\hline
\end{tabular}

Table S8. Measured ${ }^{13}$ C-DP-MAS signal areas for carboxylic and aliphatic $\mathrm{C}$ types in the in the 1L and 1-D MOF, along with average values, standard deviations and variances.

\begin{tabular}{lcccc}
\hline \multicolumn{4}{c}{ Carboxylic C } & \multicolumn{2}{c}{ Aliphatic C } \\
& \multicolumn{1}{c}{$\mathbf{1 - L}$} & $\mathbf{1 - D}$ & $\mathbf{1 - L}$ & $\mathbf{1 - D}$ \\
& $\boldsymbol{\delta}=\mathbf{1 8 9 - 1 7 3} \mathbf{~ p p m}$ & $\boldsymbol{\delta}=\mathbf{1 8 9 - 1 7 3} \mathbf{~ p p m}$ & $\boldsymbol{\delta}=\mathbf{8 0 - 6 9} \mathbf{~ p p m}$ & $\boldsymbol{\delta}=\mathbf{8 0 - 6 9} \mathbf{~ p p m}$ \\
\hline Replicate 1 & 6967183.13 & 7510833.62 & 4993318.99 & 5206554.81 \\
Replicate 2 & 7433676.59 & 7509231.17 & 4771845.89 & 5162215.27 \\
Replicate 3 & 7117876.75 & 7723402.36 & 4964346.37 & 4829527.05 \\
\hline Mean & 7172912.16 & 7581155.72 & 4909837.08 & 5066099.04 \\
Standard Deviation & 238066.61 & 123191.81 & 120378.70 & 206073.36 \\
Variance & $5.6710^{10}$ & $1.5110^{10}$ & $1.4510^{10}$ & $4.2510^{10}$ \\
\hline
\end{tabular}

Table S9. Measured ${ }^{13} \mathrm{C}-\mathrm{CP}-\mathrm{MAS}$ signal areas for carboxylic and aliphatic $\mathrm{C}$ types in the TARD ligands, along with average values, standard deviations and variances.

\begin{tabular}{lcccc}
\hline \multicolumn{3}{c}{${ }^{\mathbf{1 3}} \mathbf{C}-$ CS-CP-MAS TAR-D } \\
\hline & $\boldsymbol{\delta}=\mathbf{1 7 6 . 2 2} \mathbf{~ p p m}$ & $\boldsymbol{\delta}=\mathbf{1 7 1 . 6 4} \mathbf{~ p p m}$ & $\boldsymbol{\delta}=\mathbf{7 4 . 1 6} \mathbf{~ p p m}$ & $\boldsymbol{\delta}=\mathbf{7 1 . 6 5} \mathbf{~ p p m}$ \\
\hline Replicate 1 & 2482468.33 & 2527814.16 & 2732722.63 & 3077634.00 \\
Replicate 2 & 2514745.13 & 2440445.05 & 2822809.74 & 2900583.01 \\
Replicate 3 & 2566563.10 & 2535735.1 & 2677341.43 & 3154736.26 \\
\hline Mean & 2521258.85 & 2501331.44 & 2744291.27 & 3044317.76 \\
Standard Deviation & 42424.10 & 52877.68 & 73420.93 & 130310.97 \\
Variance & $1.8010^{9}$ & $2.8010^{9}$ & $5.3910^{9}$ & $1.7010^{10}$ \\
\hline
\end{tabular}


Table S10. Measured ${ }^{13} \mathrm{C}$-DP-MAS signal areas for carboxylic and aliphatic C types in the TARD ligands, along with average values, standard deviations and variances.

\begin{tabular}{|c|c|c|c|c|}
\hline \multicolumn{5}{|c|}{${ }^{13}$ C-SS-DP-MAS TAR-D } \\
\hline & \multicolumn{2}{|c|}{ Carboxylic C } & \multicolumn{2}{|c|}{ Aliphatic C } \\
\hline & $\delta=176.22 \mathrm{ppm}$ & $\delta=171.64 \mathrm{ppm}$ & $\delta=74.16 \mathrm{ppm}$ & $\delta=71.65 \mathrm{ppm}$ \\
\hline Replicate 1 & 572820.44 & 604999.02 & 541882.41 & 547147.43 \\
\hline Replicate 2 & 497557.49 & 614227.73 & 592199.91 & 592383.04 \\
\hline Replicate 3 & 563869.98 & 581667.65 & 545580.12 & 556986.56 \\
\hline Mean & 544755.96 & 600298.13 & 559887.48 & 565505.68 \\
\hline Standard Deviation & 41102.13 & 16781.34 & 28044.40 & 23790.68 \\
\hline Variance & $1.6910^{9}$ & $2.8210^{8}$ & $7.8610^{08}$ & $5.5610^{08}$ \\
\hline
\end{tabular}

Table S11. ${ }^{13}$ C-SS-CP-MAS Measured Signal Areas for all signals of both C types in the TAR-L ligands, along with average values, standard deviations and variances.

\begin{tabular}{lcccc}
\hline \multicolumn{4}{c}{${ }^{\mathbf{1 3}} \mathbf{C - S S}-\mathbf{C P}-M A S$ TAR-L } \\
& $\boldsymbol{\delta}=\mathbf{1 7 6 . 2 2} \mathbf{~ p p m}$ & $\boldsymbol{\delta}=\mathbf{1 7 1 . 6 4} \mathbf{~ p p m}$ & $\boldsymbol{\delta}=\mathbf{7 4 . 1 6} \mathbf{~ p p m}$ & $\boldsymbol{\delta}=\mathbf{7 1 . 6 5} \mathbf{~ p p m}$ \\
\hline Replicate 1 & 2194246.81 & 2252098.38 & 2379186.99 & 2407662.40 \\
Replicate 2 & 2167559.09 & 2049723.44 & 2246690.07 & 2598882.50 \\
Replicate 3 & 2206243.18 & 2119348.73 & 2311466.61 & 2447109.56 \\
\hline Mean & 2189349.69 & 2140390.18 & 2312447.89 & 2484551.49 \\
Standard Deviation & 19501.54 & 102815.18 & 66253.91 & 100958.93 \\
Variance & $3.9210^{8}$ & $1.0610^{10}$ & $4.3910^{9}$ & $1.0510^{10}$ \\
\hline
\end{tabular}

Table S12. ${ }^{13}$ C-SS-DP-MAS Measured Signal Areas for all signals of both C types in the TAR-L ligands, along with average values, standard deviations and variances.

\begin{tabular}{lcccc}
\hline \multicolumn{4}{c}{${ }^{\mathbf{1 3}}$ C-SS-DP-MAS TAR-L } \\
& \multicolumn{3}{c}{ Carboxylic C } & \multicolumn{2}{c}{ Aliphatic C } \\
& $\boldsymbol{\delta}=\mathbf{1 7 6 . 2 2} \mathbf{~ p p m}$ & $\boldsymbol{\delta}=\mathbf{1 7 1 . 6 4} \mathbf{~ p p m}$ & $\boldsymbol{\delta}=\mathbf{7 4 . 1 6} \mathbf{~ p p m}$ & $\boldsymbol{\delta}=\mathbf{7 1 . 6 5} \mathbf{~ p p m}$ \\
\hline Replicate 1 & 576783.89 & 583448.24 & 596442.49 & 562904.55 \\
Replicate 2 & 574343.92 & 595350.92 & 546372.01 & 570013.28 \\
Replicate 3 & 582381.07 & 654466.46 & 587072.79 & 588783.65 \\
\hline Mean & 577836.29 & 611088.54 & 576629.10 & 573900.49 \\
Standard Deviation & 4120.63 & 38034.87 & 26618.91 & 13370.29 \\
Variance & $1.7010^{7}$ & $1.4510^{9}$ & $7.0910^{8}$ & $1.7910^{8}$ \\
\hline
\end{tabular}



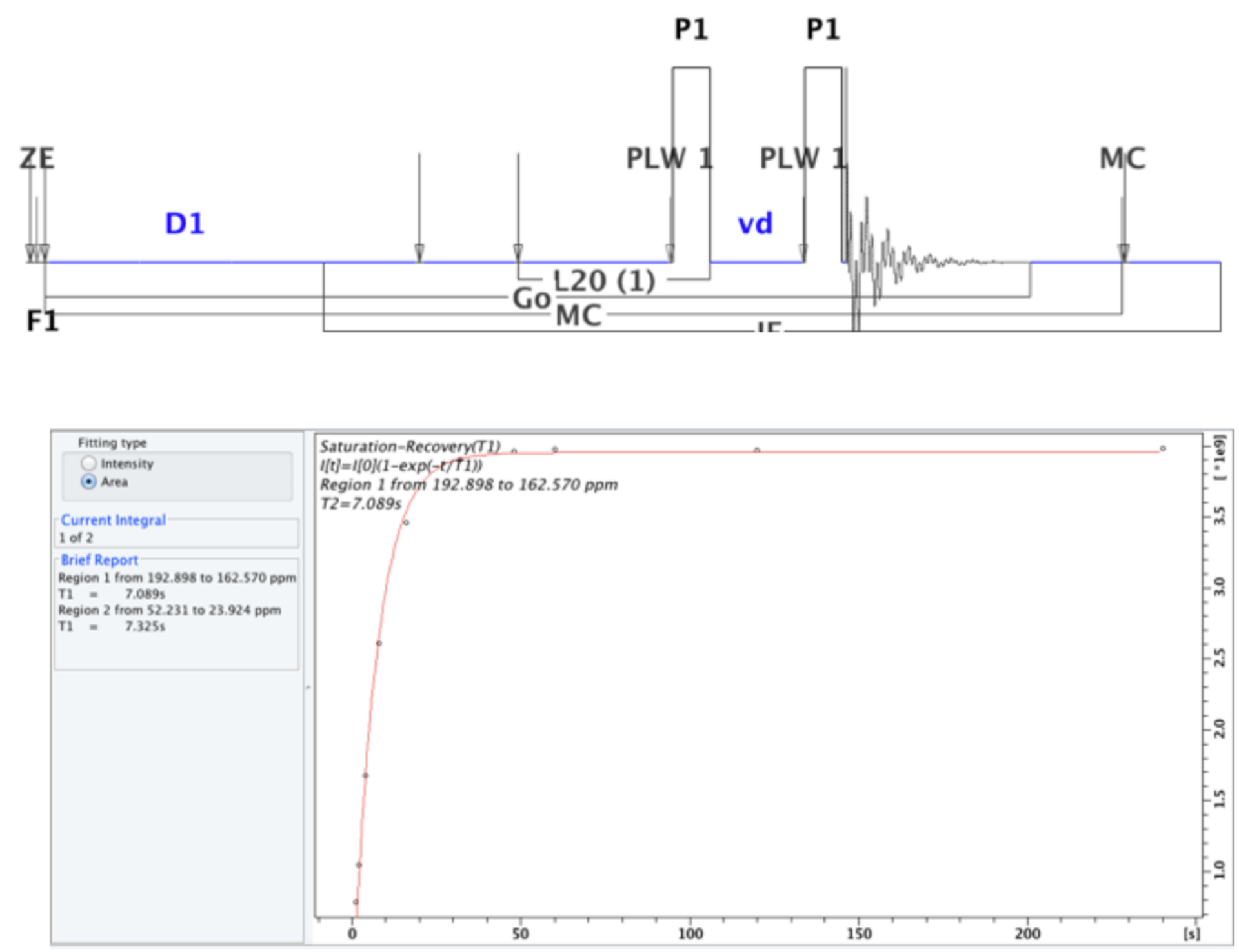

Figure S9. Saturation recovery $\mathrm{T} 1\left({ }^{13} \mathrm{C}\right){ }^{13} \mathrm{C}$-DP-MAS-SS-NMR experiment for ${ }^{13} \mathrm{C}$ enriched glycine sample. 
proton $\mathrm{T} 1$ saturation recovery with $\mathrm{cp}$ detection
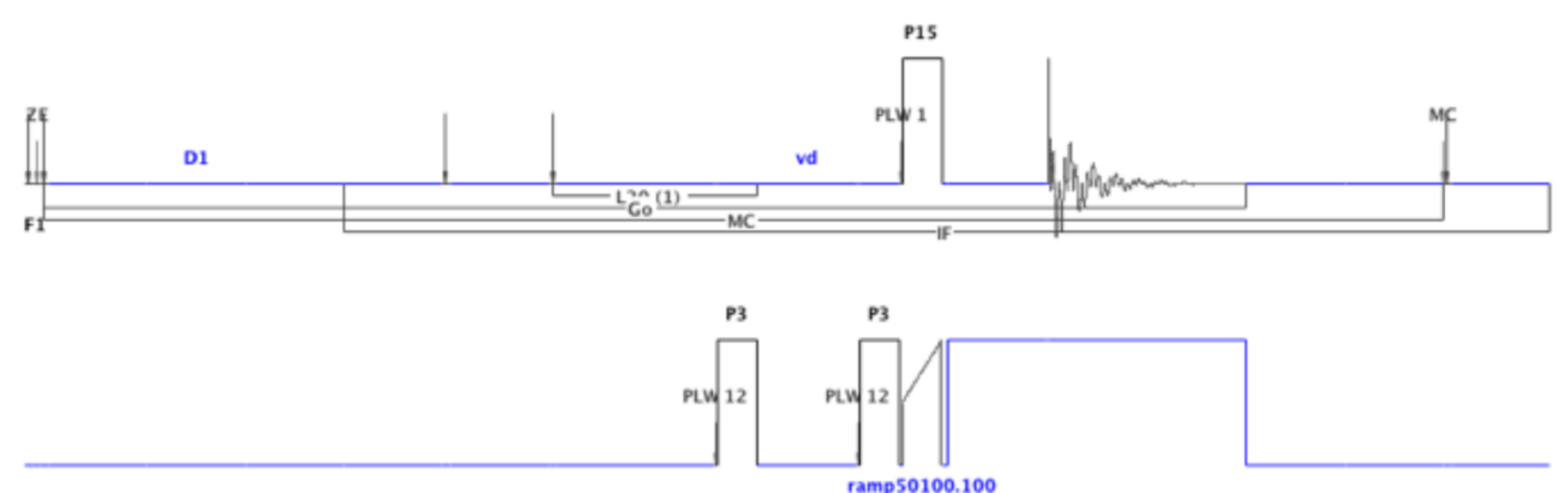

52

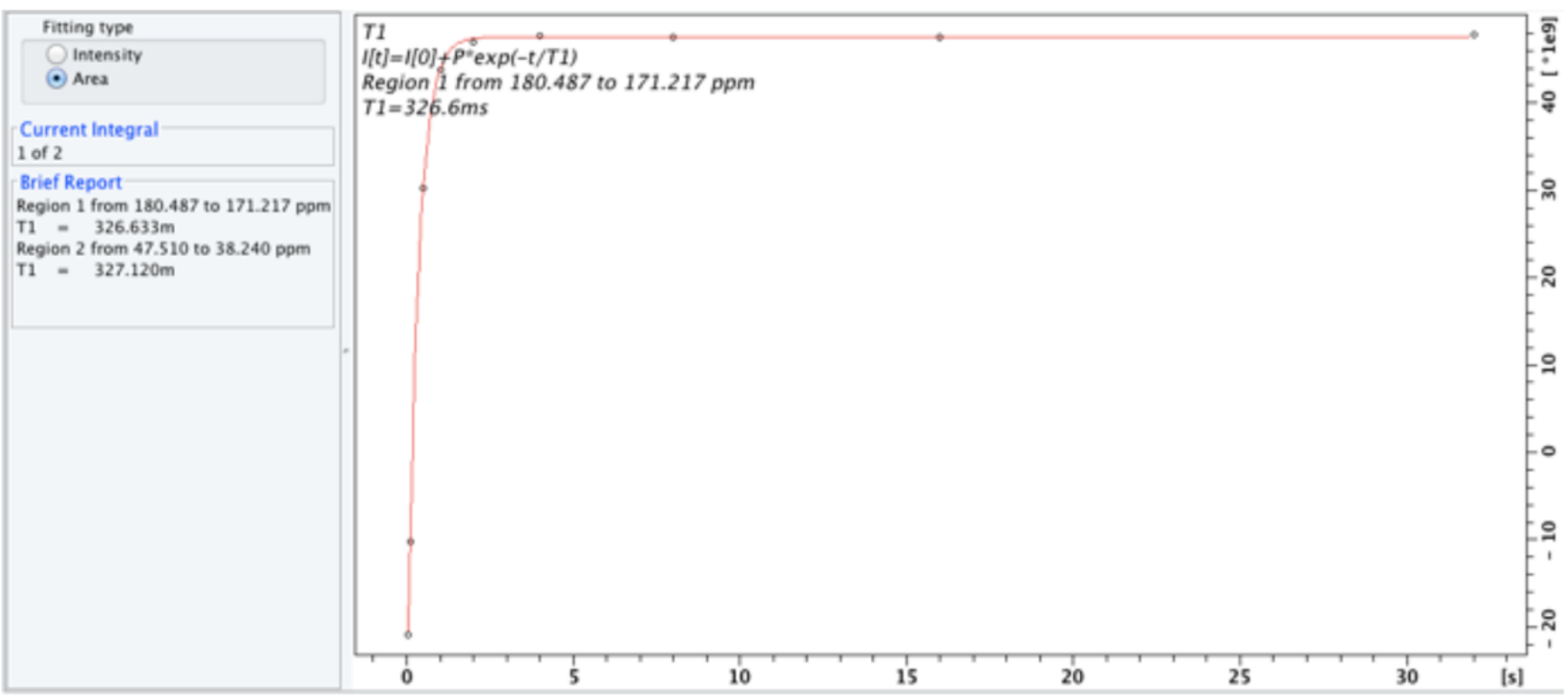

Figure S10, T1 $\left({ }^{1} \mathrm{H}\right)$ Saturation recovery with ${ }^{13} \mathrm{C}-\mathrm{CP}-\mathrm{MAS}-\mathrm{SS}-\mathrm{NMR}$ detection for ${ }^{13} \mathrm{C}$ enriched glycine sample. 

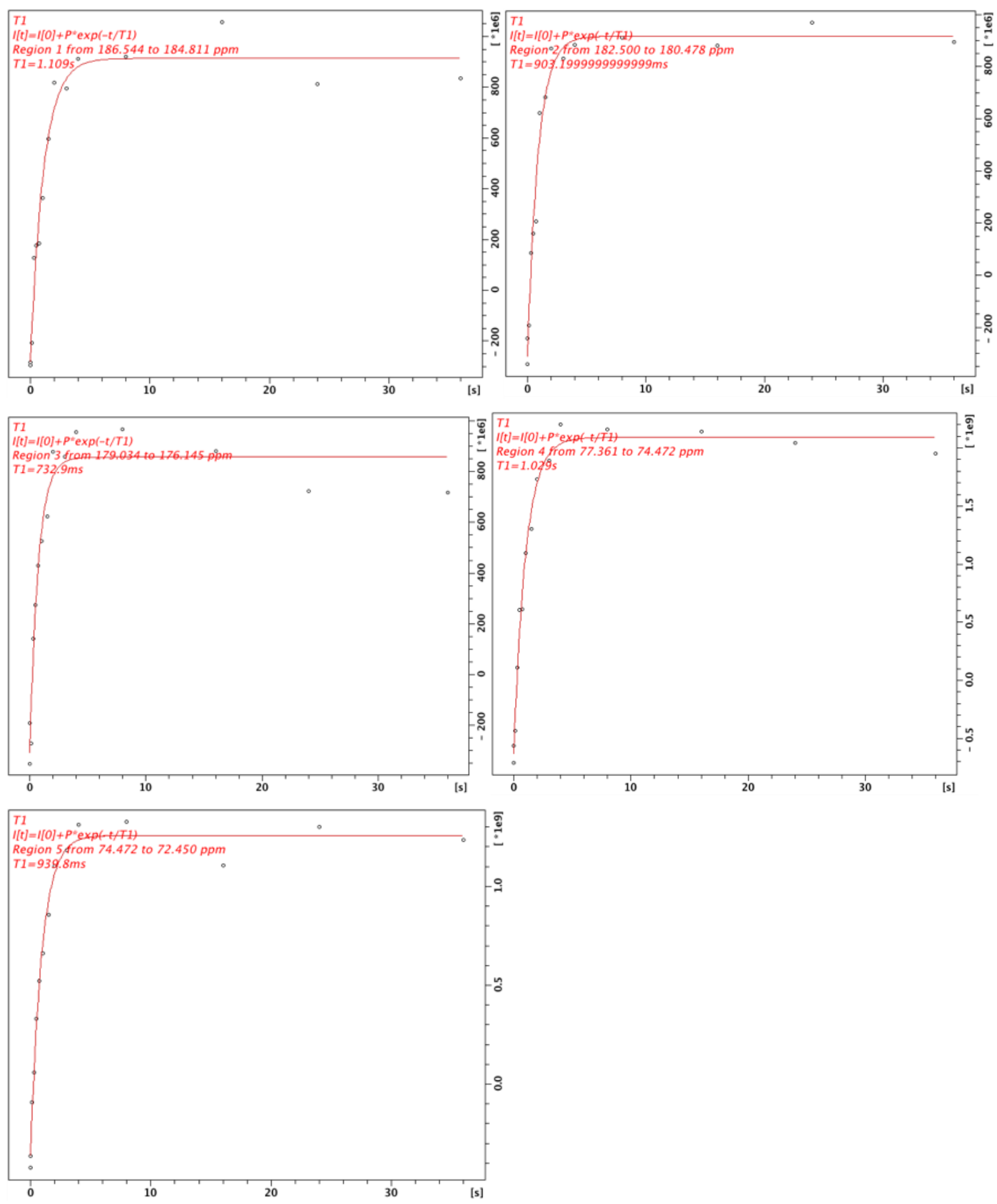

Figure S11. Measured $\mathrm{T}_{1}\left({ }^{1} \mathrm{H}\right)$ relaxation times for the 5 different regions on ${ }^{13} \mathrm{C}-\mathrm{CP}-\mathrm{MAS}-\mathrm{SS}-\mathrm{NMR}$ spectrum for 1-L compound. 

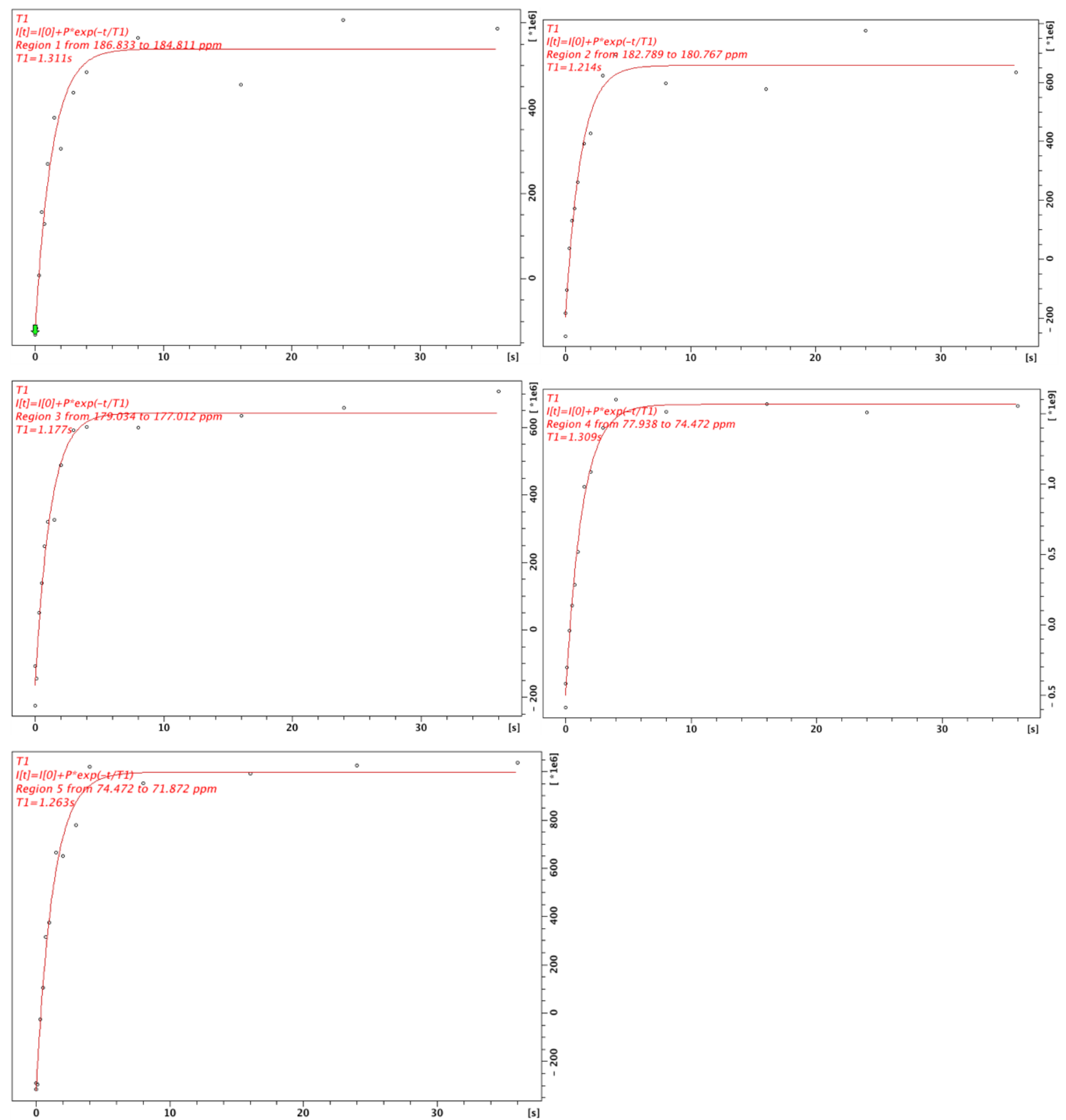

Figure S12. Measured $\mathrm{T}_{1}\left({ }^{1} \mathrm{H}\right)$ relaxation times for the 5 different regions on ${ }^{13} \mathrm{C}-\mathrm{CP}-\mathrm{MAS}-\mathrm{SS}-\mathrm{NMR}$ spectrum for 1-D compound. 

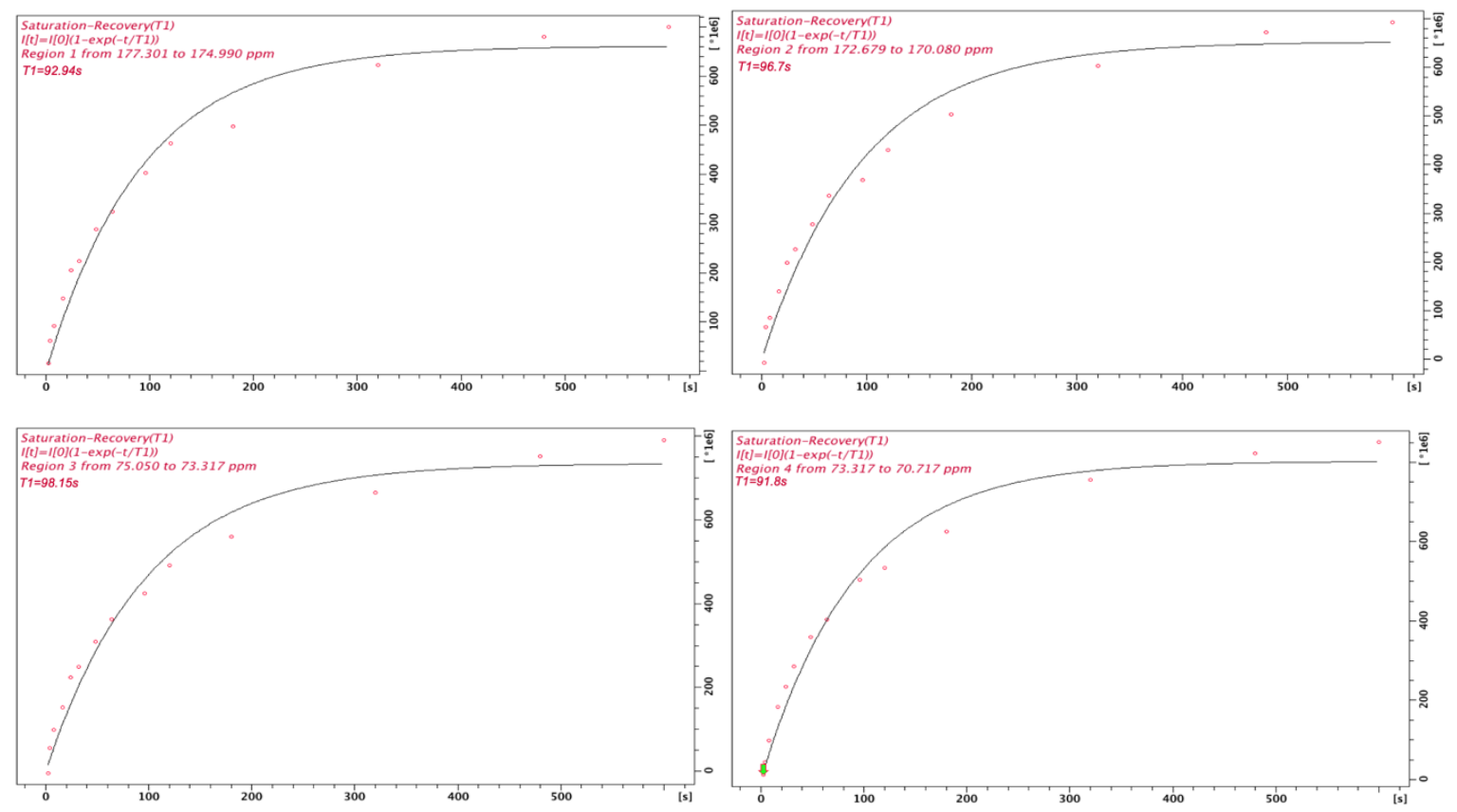

Figure S13. Measured $\mathrm{T}_{1}\left({ }^{1} \mathrm{H}\right)$ relaxation times for the 4 different regions/signals on ${ }^{13} \mathrm{C}$ NMR spectrum for TAR-L compound. 

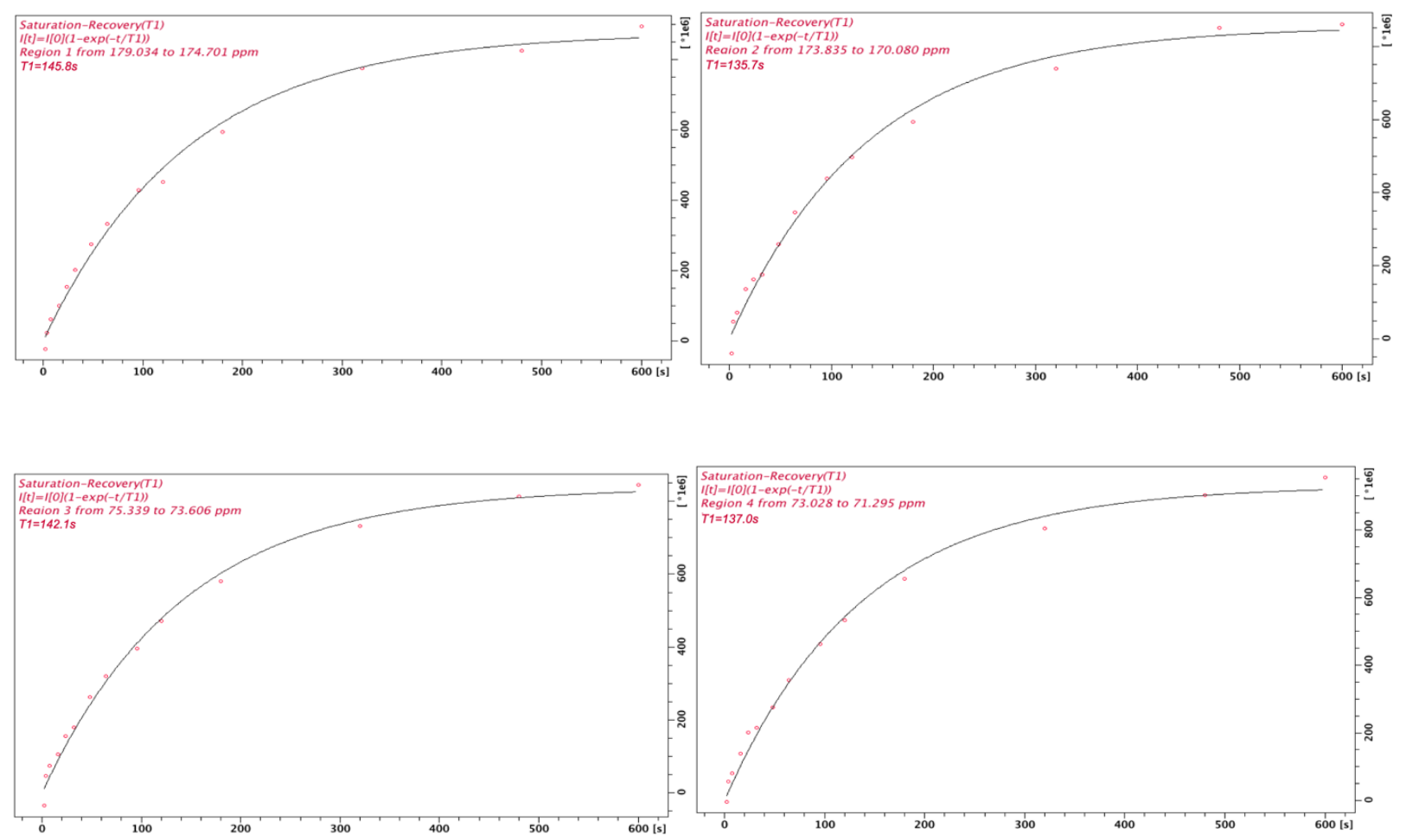

Figure S14. Measured $\mathrm{T}_{1}\left({ }^{1} \mathrm{H}\right)$ relaxation times for the 4 different regions on ${ }^{13} \mathrm{C}$ NMR spectrum for TAR-D compound.

Measurement of T1 $\left({ }^{1} \mathrm{H}\right)$ in DP-MAS experiments for 1-D and 1-L MOFs, and TAR-D and TAR-L ligands.
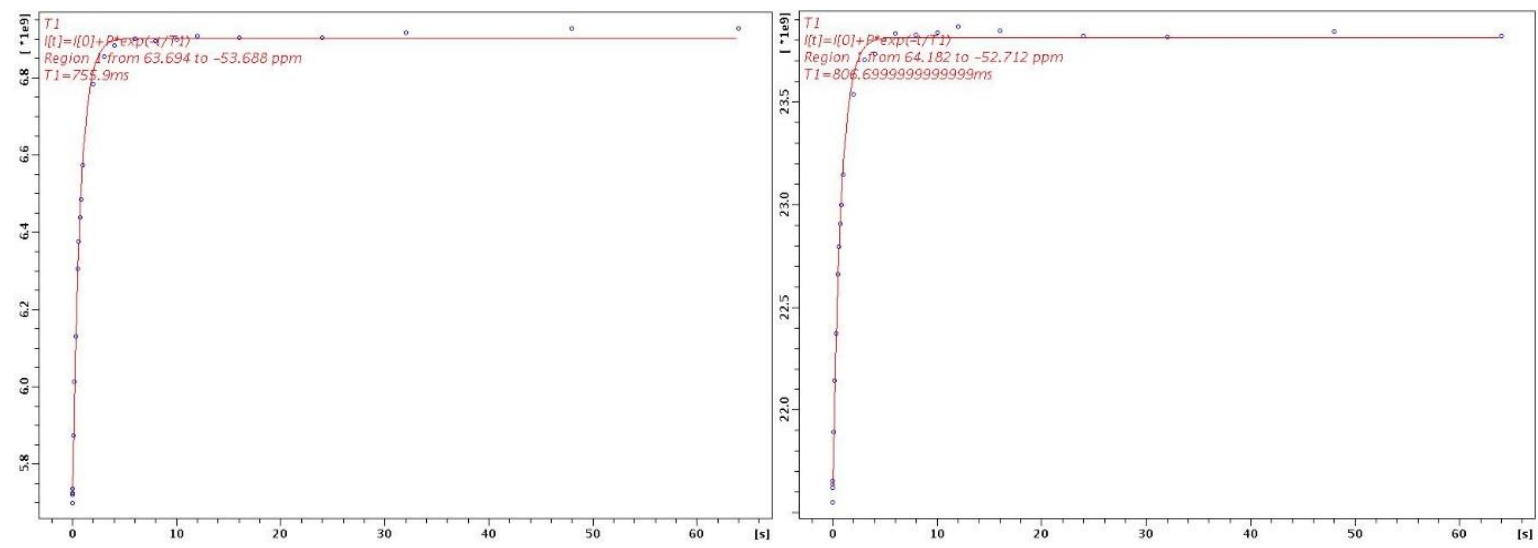

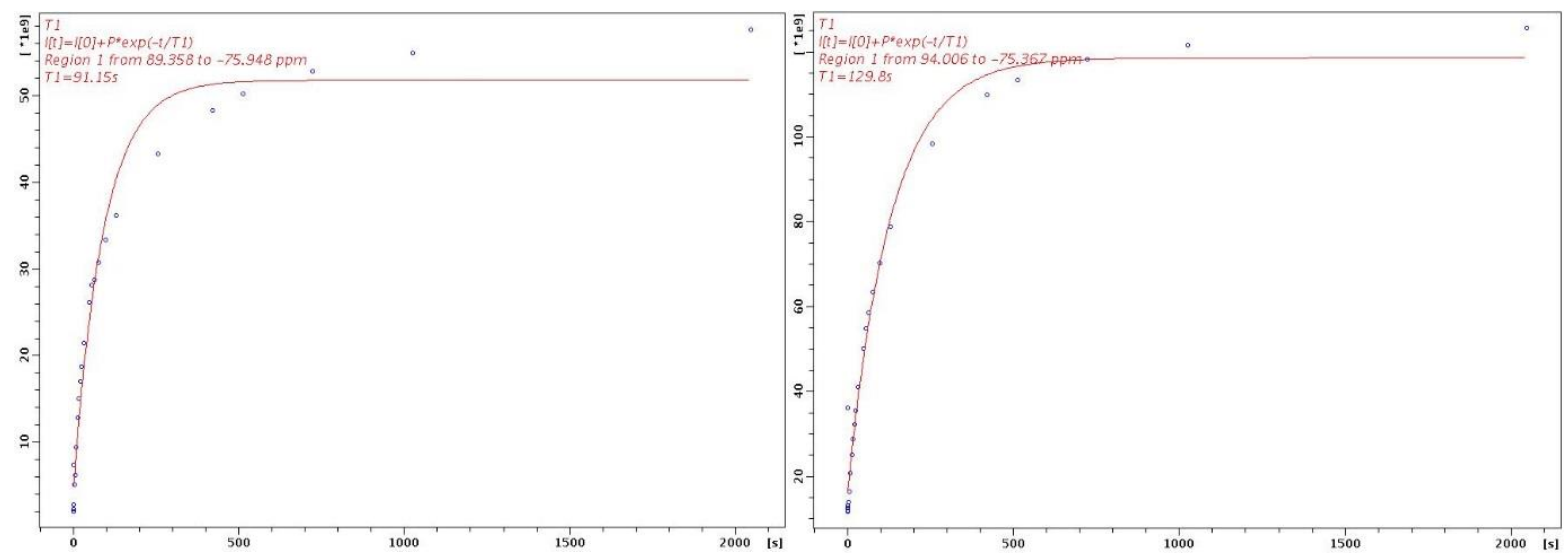

Figure S15. Measured $\mathrm{T}_{1}\left({ }^{1} \mathrm{H}\right)$ relaxation times for the 4 compounds in DP experiments. Above, from left to right, 1-L and 1-D. Below, from left to right, TAR-L and TAR-D.

Table S13. Measured $\mathrm{T}_{1}\left({ }^{1} \mathrm{H}\right)$ relaxation times for the 4 compounds

\begin{tabular}{|c|c|c|c|c|}
\hline \multicolumn{5}{|c|}{${ }^{1} \mathrm{H}-\mathrm{SS}-\mathrm{DP}-\mathrm{MAS}$} \\
\hline & 1-D & 1-L & TAR-D & TAR-L \\
\hline $\mathrm{T}_{1}\left({ }^{1} \mathrm{H}\right)(\mathrm{s})$ & 0.807 & 0.756 & 129.800 & 91.150 \\
\hline
\end{tabular}




\section{S10. Scanning Electron Microscope Imaging}

Scanning Electron Microscopy (SEM) analysis of the samples were conducted to exclude the effect of particle sizes on the nanometric scale. SEM images for the 1-L, 1-D, TAR-L and TAR-D samples were obtained, and are collected in Figure S16. As it is clear from the images, the prepared samples contain particles of diameters above $1 \mu \mathrm{m}$. Importantly, no differences in size is observed for $\mathrm{L}$ and $\mathrm{D}$ cases, where similar patterns are observed. Hence, we conclude that the size-dependency can be ruled out as a potential cause of the observed L/D signal differences.

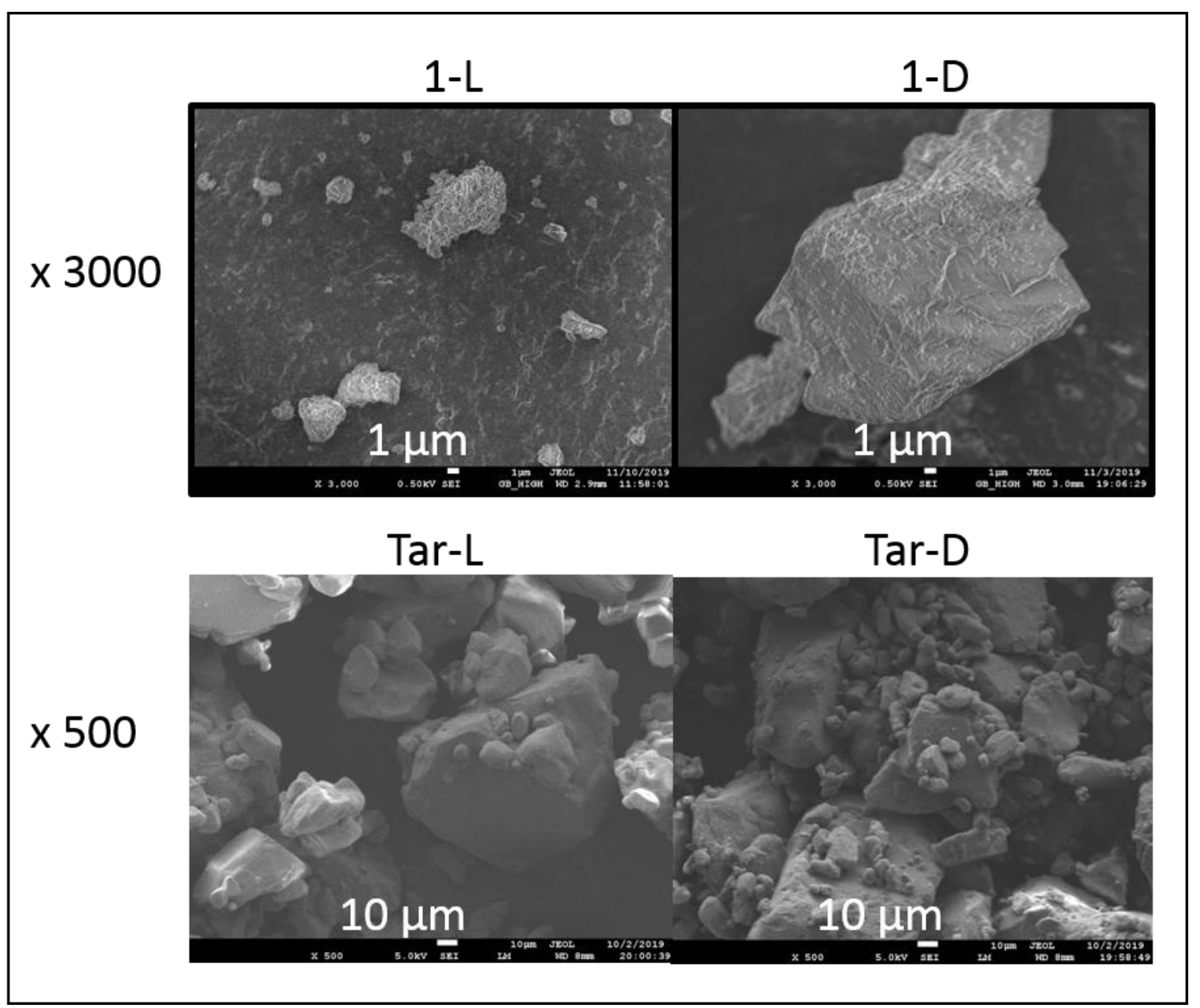

Figure S16. SEM images obtained for the 1-L, 1-D, TAR-L and TAR-D samples. 
${ }^{1}$ CrysAlisPro Software System, Agilent Technologies UK Ltd, Oxford, UK, 2012.

2 Sheldrick, G. M. Acta Cryst. A71, 3-8 (2015)

3 a) Sheldrick, G. M. SHELX-2014, Program for Crystal Structure Refinement, University of Göttingen, Göttingen, Germany, (2014). b) Farrugia, L. J. WinGX suite for smallmolecule single-crystal crystallography J. Appl. Cryst. 32, 837 (1999)

${ }^{4}$ Taylor, R.E. 13C CP/MAS: Application to Glycine. Concepts in Magnetic Resonance Part A. 22A. 37 - 49. (2004). 